This is the final peer-reviewed accepted manuscript of:

Francesco Della Monica, Bholanath Maity, Thomas Pehl, Antonio Buonerba, Assunta De Nisi, Magda Monari, Alfonso Grassi, Bernhard Rieger, Luigi Cavallo, Carmine Capacchione, [OSSO]-Type Iron(III) Complexes for the Low-Pressure Reaction of Carbon Dioxide with Epoxides: Catalytic Activity, Reaction Kinetics, and Computational Study, ACS Catalysis, 2018, 8(8), pp. 6882-6893

The final published version is available online at: https://doi.org/10.1021/acscatal.8b01695

Rights / License:

The terms and conditions for the reuse of this version of the manuscript are specified in the publishing policy. For all terms of use and more information see the publisher's website. 


\title{
[OSSO]-Type Iron(III) Complexes for the Low-Pressure Reaction of Carbon Dioxide with Epoxides: Catalytic Activity, Reaction Kinetics, and Computational Study
}

Francesco Della Monica, ${ }^{\dagger, \# \odot ~ B h o l a n a t h ~ M a i t y, ~}{ }^{\ddagger}, \#$ Thomas Pehl, ${ }^{\|}$Antonio Buonerba, ${ }^{\dagger}$ Assunta De Nisi, ${ }^{\S}$

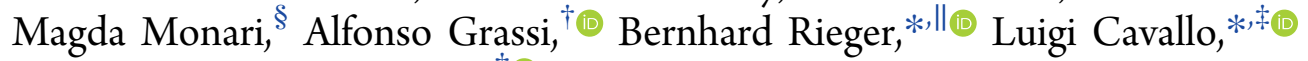
and Carmine Capacchione ${ }^{*} \dagger$ (0)

\author{
${ }^{\dagger}$ Dipartimento di Chimica e Biologia “Adolfo Zambelli”, Università degli Studi di Salerno, Via Giovanni Paolo II, 84084 Fisciano, SA, \\ Italy \\ ${ }^{\ddagger}$ KAUST Catalysis Center, King Abdullah University of Science and Technology, Thuwal 23955-6900, Saudi Arabia \\ "WACKER-Lehrstuhl für Makromolekulare Chemie, Zentralinstitut für Katalyseforschung (CRC), Technische Universitat \\ München, Lichtenbergstraße 4, 85747 Garching, Germany \\ ${ }^{\S}$ Dipartimento di Chimica G. Ciamician, Alma Mater Studiorum, Università di Bologna, via Selmi 2, 40126 Bologna, Italy
}

\begin{abstract}
The selective conversion of variously substituted epoxides into the corresponding cyclic carbonates under mild reaction conditions was achieved with mononuclear $\mathrm{Fe}$ (III) complexes bearing bis-thioether-diphenolate [OSSO]type ligands, in combination with tetrabutylammonium bromide (TBAB). For example, propylene carbonate was obtained in $1 \mathrm{~h}$ at $35^{\circ} \mathrm{C}$ (turnover frequency, TOF $=290 \mathrm{~h}^{-1}$ ), from propylene oxide and 1 bar of $\mathrm{CO}_{2}$ pressure, using $0.1 \mathrm{~mol}$ $\%$ of the $\mathrm{Fe}(\mathrm{III})$ complex and $0.5 \mathrm{~mol} \%$ of TBAB. Product

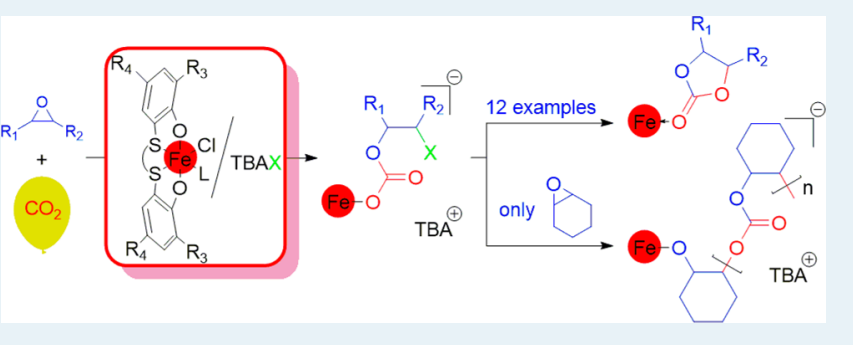
divergence is observed only for cyclohexene oxide toward the exclusive formation of the aliphatic polycarbonate (TOF $=165$ $\mathrm{h}^{-1}$ at $80{ }^{\circ} \mathrm{C}$ and 1 bar of $\mathrm{CO}_{2}$ pressure, using $0.1 \mathrm{~mol} \%$ of the $\mathrm{Fe}(\mathrm{III})$ complex and $0.1 \mathrm{~mol} \%$ of tetrabutylammonium chloride). Kinetic investigations indicated reaction orders of two and one, with respect to the Fe(III) complex, for the production of propylene carbonate and the poly(cyclohexene carbonate), respectively. The enthalpy and entropy of activation were determined using the Eyring equation [for propylene carbonate: $\Delta H^{\ddagger}=8.4 \pm 0.7 \mathrm{kcal} / \mathrm{mol}$ and $\Delta S^{\ddagger}=-33 \pm 3 \mathrm{cal} /(\mathrm{mol}$. $\mathrm{K}$ ); for poly(cyclohexene carbonate): $\Delta H^{\ddagger}=11.9 \pm 0.3 \mathrm{kal} / \mathrm{mol}$ and $\left.\Delta S^{\ddagger}=-36 \pm 2.2 \mathrm{cal} /(\mathrm{mol} \cdot \mathrm{K})\right]$. Supported by density functional theory based investigations, we propose a mechanistic scenario in which the rate-limiting step is the bimetallic ring opening of the epoxide, in the case of propylene carbonate, and the monometallic insertion of the epoxide in the growing polymer chain, in the case of poly(cyclohexene carbonate).
\end{abstract}

KEYWORDS: iron, carbon dioxide, cycloaddition, polymerization, mechanism, kinetics, DFT

\section{INTRODUCTION}

The last two decades have witnessed growing interest in the capture and utilization of carbon dioxide $\left(\mathrm{CO}_{2}\right){ }^{1}$ This strategy, the so-called carbon dioxide utilization (CDU), offers a conceptually simple way to reduce anthropogenic $\mathrm{CO}_{2}$ emissions, with the advantage of using an abundant nontoxic C1 chemical feedstock for the production of added-value products, such as fuels, chemicals, and materials. ${ }^{2}$ However, implementing processes based on the $\mathrm{CO}_{2}$ chemistry is hampered by the thermodynamic stability and the kinetic inertness of this molecule. ${ }^{3}$ Two of the principal strategies to overcome the thermodynamic stability of $\mathrm{CO}_{2}$ are the electrochemical reduction of $\mathrm{CO}_{2}$, where the applied potential provides the thermodynamic driving force, ${ }^{4}$ or targeting reactions where $\mathrm{CO}_{2}$ is coupled with a thermodynamically unstable molecule, which provides the thermodynamic driving force toward value-added chemicals. ${ }^{5}$ A representative example of this concept is the coupling of $\mathrm{CO}_{2}$ with epoxides to give cyclic organic carbonates (COCs), ${ }^{6}$ or aliphatic polycarbonates (APCs). ${ }^{7}$ COCs have many applications as highly boiling polar solvents, ${ }^{8}$ electrolytes in lithium-ion batteries, ${ }^{9}$ and chemical intermediates in the synthesis of other industrially relevant products. ${ }^{10}$ On the other hand, APCs have several applications as materials, ${ }^{11}$ and can also be used to store $\mathrm{CO}_{2}$ for a longer range of time with respect to small molecules because of the long lasting life of these polymers. ${ }^{12}$

The kinetic inertness of $\mathrm{CO}_{2}$ can be overcome by developing effective catalytic systems. Those for the synthesis of COCs 
and APCs are generally based on the combination of a transition-metal complex with a nucleophile (quaternary ammonium salts and phosphonium salts) as cocatalyst, with several metals known to perform effectively (e.g., Al, $\mathrm{Zn}, \mathrm{Co}$, and $\mathrm{Cr}$ ). ${ }^{6 e, 7 \mathrm{f}} \mathrm{It}$ is widely accepted that these reactions proceed through a mechanism involving the following fundamental steps (Scheme 1): ${ }^{6 \mathrm{~b}}$ (a) the epoxide ring coordinates to the

Scheme 1. General Mechanism for the Coupling of $\mathrm{CO}_{2}$ and Epoxides $^{a}$

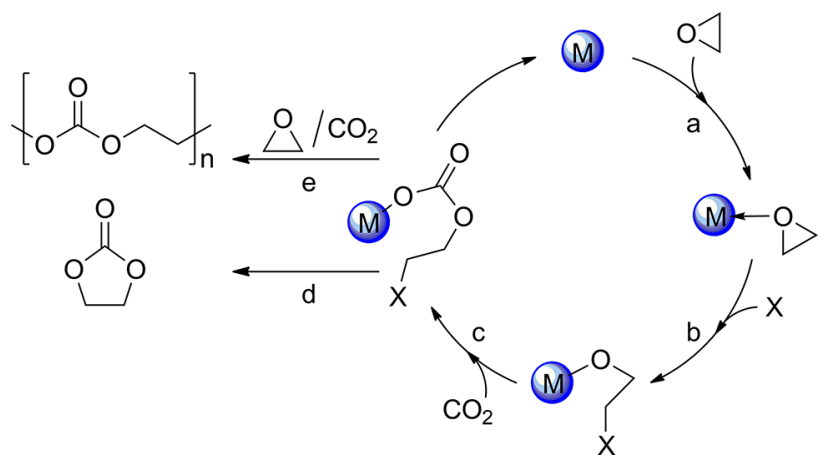

${ }^{a}$ Abbreviations: $\mathrm{M}=$ metal complex; $\mathrm{X}=$ nucleophile.

Lewis acidic metal center; (b) the activated epoxide reacts with the nucleophilic cocatalyst to generate a metal-alcoholate species; (c) the insertion of $\mathrm{CO}_{2}$ into the metal-oxygen bond leads to the formation of a hemicarbonate intermediate. The latter may undergo two different reactions: (d) ring closure, with formation of the cyclic carbonate, or (e) the alternate insertion of the epoxide and $\mathrm{CO}_{2}$, affording polycarbonate architectures.

In spite of several studies aimed to clarify the mechanistic aspects of the $\mathrm{CO}_{2}$ /epoxide coupling reaction, a widely accepted mechanistic scenario, including the comprehension of the factors governing the selectivity toward the cyclic or polymeric product, is still lacking. Nevertheless, in many cases the use of a bimetallic catalytic system with two proximal metal centers seems to have a fundamental role in both the cyclization and copolymerization reactions. ${ }^{13}$ In the first case, North and Pasquale reported a bimetallic aluminum(salen) complex for the synthesis of styrene carbonate in which one metal center activates the epoxide and the other one promotes the $\mathrm{CO}_{2}$ insertion into the metal-alkoxide bond. ${ }^{13 a}$ In the second case, Williams and co-workers described the use of a bimetallic zinc complex for the production of poly(cyclohexene carbonate), claiming that a bimetallic mechanism is crucial for both the initiation and propagation steps. ${ }^{13 \mathrm{~b}}$ Specifically, during the initiation step one metal center activates the epoxide and the second one furnishes the nucleophile for the ring opening, while in the propagation step one metal activates the epoxide, and the second one, bearing the growing polycarbonate chain, activates the carbonate end group for the nucleophilic attack. ${ }^{13 \mathrm{c}}$ The presence of a dinuclear catalytic system is also reported to prevent the backbiting reaction responsible for the formation of mixtures of cyclic and polymeric products. $^{7 \mathrm{c}}$ The occurrence of a bimetallic mechanism was demonstrated even in the presence of mononuclear complexes, as reported by Coates and coworkers ${ }^{14}$ and Rieger and co-workers, ${ }^{15}$ for the production of poly(propylene carbonate) and propylene carbonate, respectively. Recently, we reported on a family of dinuclear Fe(III) complexes coordinated by bis-thioether-triphenolate ligands that, in combination with tetrabutylammonium bromide (TBAB), have shown to be highly active in the synthesis of various COCs from terminal and internal epoxides. ${ }^{16}$ Intriguingly, mechanistic studies through density functional theory (DFT)-based calculations have evidenced not only the crucial role of the hemilabile $\mathrm{Fe}-\mathrm{S}$ bond in the catalytic activity but also that only one metal center is active in the catalytic cycle. $^{17}$

Inspired from these findings, and encouraged by the fact that different examples of highly active catalysts in both the cyclization and copolymerization reactions have been reported for which a monometallic mechanism has been proposed, ${ }^{18}$ our attention has thus moved to the synthesis of mononuclear iron(III) complexes containing sulfur atoms in the ligand backbone. In particular, in this work we report on the synthesis and complete characterization of a new family of [OSSO]-type iron(III) complexes and their use, when combined with suitable halide nucleophiles, as highly efficient binary catalysts for COCs formation for a wide range of substrates under very mild reaction conditions, recording the highest turnover frequency (TOF) values ever reported under 1 bar of $\mathrm{CO}_{2}$ pressure. Furthermore, these catalysts also promote the efficient copolymerization of cyclohexene oxide with $\mathrm{CO}_{2}$, giving the corresponding polycarbonate with highest activity and selectivity so far reported for iron-based catalysts. A complete kinetic investigation was conducted for both the cyclization and copolymerization reactions and a mechanistic scenario is proposed, combining experimental evidence with DFT-based calculations.

\section{RESULTS AND DISCUSSION}

Synthesis and Characterization of the [OSSO]-Fe(III) Complexes 1-4. The bis-thioether-diphenolate [OSSO]type pro-ligand $\mathbf{L} \mathbf{1}$, with bulky trityl substituents in the $\mathrm{R}_{1}$ positions, and pro-ligands $\mathbf{L} 2-\mathbf{L} 4$ were synthesized according to the reported procedures (see Supporting Information). ${ }^{19}$ The mononuclear [OSSO]-Fe complexes 1-4 were obtained by reaction of $\mathrm{FeCl}_{3}$ with the sodium salt of the corresponding pro-ligand in THF solution; all the products were recovered in high yield (90-97\%) as deep-blue powders (Scheme 2).

Scheme 2. Synthesis of the Iron(III) Complexes 1-4

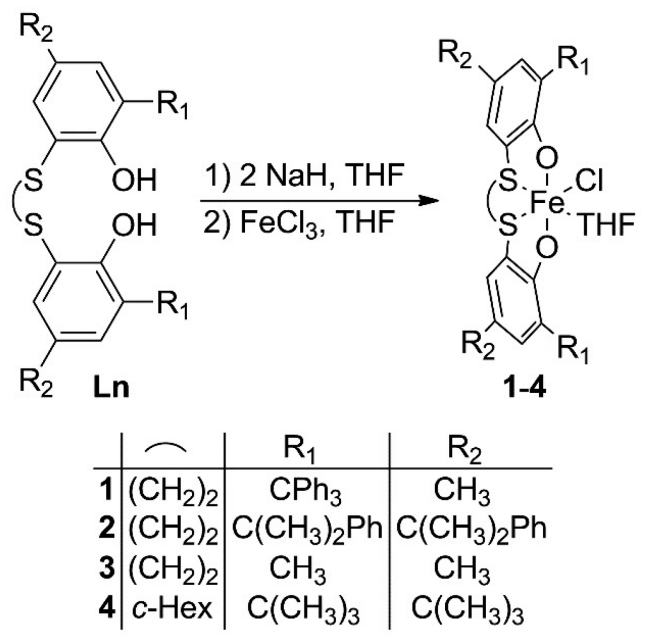


Single crystals of the complex 2 were grown from a saturated acetonitrile solution, and the crystal structure is shown in Figure 1.

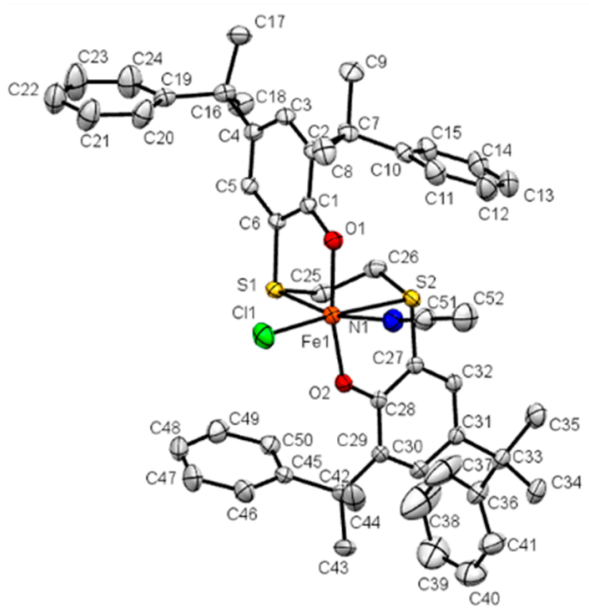

Figure 1. Molecular structure of compound 2. Hydrogen atoms have been omitted for the sake of clarity (thermal ellipsoids are drawn at $30 \%$ of the probability level). Selected bond lengths $(\AA)$ and angles (deg): $\mathrm{Fe}_{1}-\mathrm{O}_{1}$ 1.908(2), $\mathrm{Fe}_{1}-\mathrm{O}_{2}$ 1.900(2), $\mathrm{Fe}_{1} \mathrm{~S}_{1}$ 2.5642(8), $\mathrm{Fe}_{1}-\mathrm{S}_{2}$ 2.6936(9), $\mathrm{Fe}_{1}-\mathrm{Cl}_{1}$ 2.2497(9), $\mathrm{Fe}_{1}-\mathrm{N}_{1}$ 2.124(2), $\mathrm{S}_{1}-\mathrm{Fe}_{1}-\mathrm{S}_{2}$ $83.20(2)$.

The $\mathrm{Fe}$ atom has a distorted octahedral geometry being coordinated by one tetradentate [OSSO] ligand adopting a $f a c-f a c$ wrapping coordination mode, one chloride, and one $\mathrm{N}$ atom from an acetonitrile ligand. The $\mathrm{Fe}$ atom is involved in a puckered five-membered ring $\left(\mathrm{Fe}_{1}-\mathrm{S}_{1}-\mathrm{C}_{25}-\mathrm{C}_{26}-\mathrm{S}_{2}\right)$ with a $S_{1}-F_{1}-S_{2}$ bite angle of $83.20(2)^{\circ}$, smaller than that found for example in the complex $\left[\mathrm{Fe}(\mathrm{CO})_{2}\left(\mathrm{tbu}_{4}-\mathrm{dttd}\right)\right] .^{20}$ The elemental analysis was in agreement with the formation of the desired products, and the disappearance of the hydroxyl group vibration at about $3300 \mathrm{~cm}^{-1}$ is evident in the Fourier transform infrared (FT-IR) spectra of the complexes (see Supporting Information). The formation of a monomeric structure was confirmed by the ESI FT-ICR MS analysis from $\mathrm{CH}_{2} \mathrm{Cl}_{2} / \mathrm{MeOH}$ solutions (see Supporting Information). In addition, the effective magnetic moments $\left(\mu_{\text {eff }}\right)$, determined by means of the Evans method in deuterated toluene in the temperature range from 30 to $90{ }^{\circ} \mathrm{C}$, are comparable to the calculated value for one isolated high-spin (HS) $\mathrm{Fe}$ (III) center (see Supporting Information).

Cycloaddition of $\mathrm{CO}_{2}$ to Epoxides Catalyzed by 1-4. The cycloaddition of carbon dioxide to 1,2-epoxyhexane (5a) in the presence of 1-4 was investigated under very mild reaction conditions, that is, $35^{\circ} \mathrm{C}, 1$ bar of $\mathrm{CO}_{2}$ pressure, and $0.1 \mathrm{~mol} \%$ of complex with respect to the epoxide. In the absence of cocatalyst, all the epoxide remained unreacted after $24 \mathrm{~h}$. One equivalent of TBAB activates the complexes, with the selective conversion of $\mathbf{5 a}$ to the corresponding cyclic carbonate 4-butyl-1,3-dioxolan-2-one (6a) (entries 1-4, Table S2). Under these conditions the catalyst 4 resulted in it being the most efficient with a TOF of $13.5 \mathrm{~h}^{-1}$. The variance of the catalytic activity of $\mathbf{4}$ with respect to the temperature, in the range from 20 to $70{ }^{\circ} \mathrm{C}$, was also monitored (entries 4-7, Table S2). One can observe that the activity increases linearly until $50{ }^{\circ} \mathrm{C}$, while a deviation from linearity was observed at 70 ${ }^{\circ} \mathrm{C}$.
With the aim to find the best catalyst/cocatalyst combination, the screening of the following cocatalysts, in the presence of $\mathbf{4}$ under the same reaction conditions, was also performed: dimethylaminopyridine (DMAP), bis(triphenylphosphine)-iminium chloride $([\mathrm{PPN}] \mathrm{Cl})$, tetrabutylammonium azide $\left(\mathrm{TBAN}_{3}\right)$, tetrabutylammonium chloride (TBAC), and tetrabutylammonium iodide (TBAI) (entries 812, Table S2). With the exception of DMAP, which poorly activates the complex, the efficiency of the catalytic system does not vary remarkably by changing the nature of the cocatalyst. Notably, increasing the TBAB amount from 0.1 to $0.5 \mathrm{~mol} \%$ positively affects the catalytic activity, enhancing the conversion from 32 to $89 \%$ (entries 4 and 14, Table S2); another increase to $1.0 \mathrm{~mol} \%$ slightly affects the progress of the reaction, reaching a conversion of $93 \%$ (entry 15 , Table S2).

The catalytic performances of $\mathbf{1 - 4}$ were compared, determining the conversion of $\mathbf{5 a}$ to $\mathbf{6 a}$ after $6 \mathrm{~h}$ (Table 1). All the complexes showed high activity, catalyst 4 being the most efficient with a TOF equal to $63 \mathrm{~h}^{-1}$.

Table 1. 5a/ $\mathrm{CO}_{2}$ Coupling Promoted by $1-4^{a}$

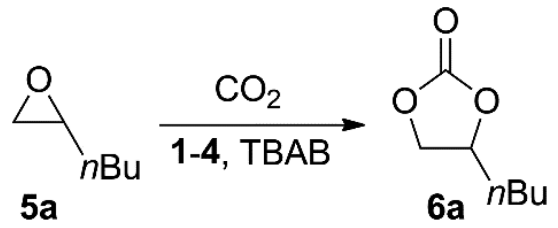

$\begin{array}{cccc}\text { entry } & \text { catalyst } & \text { conversion }(\%)^{b} & \text { TOF }\left(\mathrm{h}^{-1}\right)^{c} \\ 1 & \mathbf{1} & 33 & 55 \\ 2 & 2 & 27 & 45 \\ 3 & 3 & 32 & 53 \\ 4 & 4 & 38 & 63 \\ 5^{d} & 4 & 10 & 100 \\ 6^{e} & & 2 & \end{array}$

${ }^{a}$ Reaction conditions: $5 \mathbf{a}=4.15 \times 10^{-2} \mathrm{~mol}$; catalyst $=4.15 \times 10^{-5}$ $\mathrm{mol}(0.1 \mathrm{~mol} \%) ; \mathrm{TBAB}=2.07 \times 10^{-4} \mathrm{~mol}(0.5 \mathrm{~mol} \%) ; \mathrm{T}=35^{\circ} \mathrm{C}$; $P\left(\mathrm{CO}_{2}\right)=1$ bar; reaction time $=6 \mathrm{~h}$, neat. ${ }^{b}$ Determined by ${ }^{1} \mathrm{H}$ NMR using mesitylene as internal standard. The selectivity toward the formation of 6 a was always found to be $>99 \%$. ${ }^{c}$ Turnover frequency $\left(\mathrm{mol}_{6 \mathrm{a}} \cdot \mathrm{mol}_{\text {Catalyst }}{ }^{-1} \cdot\right.$ reaction time $\left.{ }^{-1}\right) \cdot{ }^{d}$ Reaction time $=1 \mathrm{~h} .{ }^{e}$ Control experiment in the absence of the iron catalyst.

For this catalyst, the initial TOF was determined at the reaction time of $1 \mathrm{~h}$ (entry 5, Table 1 ), reaching the value of $100 \mathrm{~h}^{-1}$. Complex 4 was then tested, in combination with $\mathrm{TBAB}$, for the conversion of a group of variously substituted epoxides in the corresponding COCs (Scheme 3). The reaction of the less encumbered propylene oxide $\mathbf{5 b}$ proceeds faster, with an initial TOF of $290 \mathrm{~h}^{-1}$. To the best of our knowledge, this is the highest activity reported so far, for a homogeneous catalyst, for the formation of $\mathbf{6 b}$ from $\mathbf{5 b}$ under 1 bar of $\mathrm{CO}_{2}$ pressure. $^{6 \mathrm{e}} \mathrm{A}$ small attenuation in the catalytic activity was observed in the case of the phenyl-substituted substrates 5c and 5d. Comparable catalytic activity was observed for the methoxy-containing epoxide 5e. For the production of allyloxy- and furfuryl-substituted carbonates $\mathbf{6 f}$ and $6 \mathrm{~g}$, the use of $0.2 \mathrm{~mol} \%$ of 4 was necessary. The formation of $6 \mathbf{h}$ proceeds slower, as reported for other catalytic systems. ${ }^{21}$

The synthesis of disubstituted carbonates $6 \mathbf{i}-\mathbf{6 k}$, known to be more challenging to obtain, was successfully accomplished at $50{ }^{\circ} \mathrm{C}$ and 10 bar of $\mathrm{CO}_{2}$ pressure, with good activities. In 
Scheme 3. Scope in Epoxides ${ }^{a}$
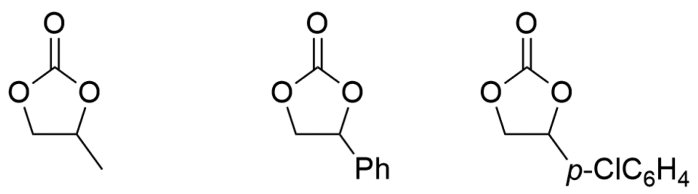

6b; yield: 29b; 65\%

6c; conv: $26 ; 55^{\mathrm{c} \%}$

6d ${ }^{\mathrm{d}}$; conv: $32 \%$

TOF $=290^{\text {b }} ; 108 \mathrm{~h}^{-1}$ TOF $=43 ; 23^{\mathrm{c}} \mathrm{h}^{-1}$

TOF $=53 \mathrm{~h}^{-1}$

$4=0.1 \mathrm{~mol} \%$

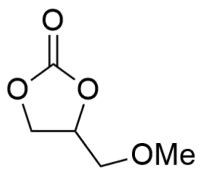

$4=0.1 \mathrm{~mol} \%$

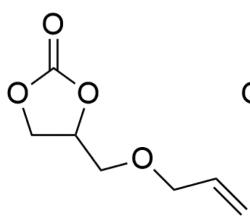

6e; conv: $35 ; 84^{\mathrm{c}} \%$

TOF $=58 ; 35^{c} \mathrm{~h}^{-1}$

6f; conv: $63 \%$

TOF $=53 \mathrm{~h}^{-1}$

$4=0.2 \mathrm{~mol} \%$
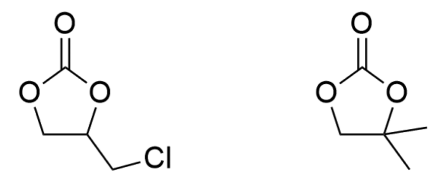

$4=0.1 \mathrm{~mol} \%$

O

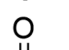

신

6g ${ }^{\mathrm{d}}$; conv: $83 \%$

TOF $=69 \mathrm{~h}^{-1}$

$4=0.2 \mathrm{~mol} \%$

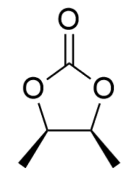

6h; conv: $20 ; 66^{\mathrm{c}} \%$

TOF $=17 ; 14^{\mathrm{c}} \mathrm{h}^{-1}$

$4=0.2 \mathrm{~mol} \%$

6ie
TOF $=34^{f} \cdot 15 h^{-1}$

$4=0.2 \mathrm{~mol} \%$

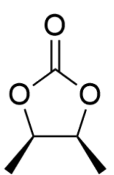

6je,h; conv: $66 \%$

TOF $=14 \mathrm{~h}^{-1}$

cis:trans $=98: 2$

$4=0.2 \mathrm{~mol} \%$

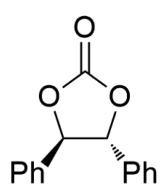

6ki conv: $21 \%$

TOF $=4 \mathrm{~h}^{-1}$

cis:trans $=11: 89$

$4=0.2 \mathrm{~mol} \%$ 6je,g; conv: $22 \%$

TOF $=4.5 \mathrm{~h}^{-1}$

cis:trans $=90: 10$

$4=0.2 \mathrm{~mol} \%$

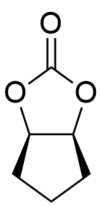

6ij; conv: $72 \%$

TOF $=15 \mathrm{~h}^{-1}$

cis:trans $=>99: 1$

$4=0.2 \mathrm{~mol} \%$
${ }^{a}$ Reaction conditions: epoxide $=4.15 \times 10^{-2} \mathrm{~mol} ; \mathrm{T}=35^{\circ} \mathrm{C} ; \mathrm{P}\left(\mathrm{CO}_{2}\right)$ $=1 \mathrm{bar}$; reaction time $=6 \mathrm{~h}$, neat. Conversion determined by ${ }^{1} \mathrm{H}$ NMR using mesitylene as internal standard. The selectivity toward the formation of cyclic carbonate was always found $>99 \%$. Stereoselectivity determined by ${ }^{1} \mathrm{H}$ NMR. ${ }^{b}$ Reaction time $=1 \mathrm{~h}$. ${ }^{c}$ Reaction time $=24 \mathrm{~h} .{ }^{d}$ Epoxide $=1.5 \mathrm{~g} .{ }^{e}$ Epoxide $=1.0 \mathrm{~mL} ; \mathrm{T}=50{ }^{\circ} \mathrm{C}$; $P\left(\mathrm{CO}_{2}\right)=10$ bar; reaction time $=24 \mathrm{~h} .{ }^{f}$ Reaction time $=4 \mathrm{~h}$. ${ }^{g}[\mathrm{TBAB}] /[4]=1 / 1 .{ }^{h}[\mathrm{TBAB}] /[4]=5 / 1 .{ }^{i}$ Epoxide $=1.0 \mathrm{~g} ; \mathrm{T}=90$ ${ }^{\circ} \mathrm{C} ; \mathrm{P}\left(\mathrm{CO}_{2}\right)=10 \mathrm{bar}$; reaction time $=24 \mathrm{~h} .{ }^{j} \mathrm{~T}=50^{\circ} \mathrm{C} ; \mathrm{P}\left(\mathrm{CO}_{2}\right)=10$ bar; reaction time $=24 \mathrm{~h}$.

particular, 6j was obtained with a high degree of stereoretention with respect to the starting epoxide, even when an equimolar mixture of 4 and TBAB was used. The formation of the bulky carbonate $6 \mathbf{k}$ requires higher temperatures to melt the epoxide, and also in this case the product was obtained with a high degree of stereoretention. The reaction of cyclopentene oxide (51) proceeds as well, with the selective formation of the corresponding cyclic carbonate 61. Intriguingly, the reaction of cyclohexene oxide $(5 \mathrm{~m})$, under the same reaction conditions, led to the exclusive formation of almost perfect poly(cyclohexene carbonate) (6m) (entry 1 Table S3). Such divergence in the selectivity was often reported for this substrate, ${ }^{22,18 \mathrm{e}}$ but the examples of iron-based catalytic systems capable of copolymerizing $\mathbf{5 m}$ with $\mathrm{CO}_{2}$ are rather rare. ${ }^{23}$
Copolymerization of $5 \mathrm{~m}$ and $\mathrm{CO}_{2}$ Catalyzed by 1-4.

To gain deeper insight into the behavior of this new family of catalysts, the copolymerization reaction of $\mathrm{CO}_{2}$ with $5 \mathrm{~m}$ in the presence of $1-4$ at $80{ }^{\circ} \mathrm{C}$ and 10 bar of $\mathrm{CO}_{2}$ pressure was performed, using $0.1 \mathrm{~mol} \%$ of complex and $0.1 \mathrm{~mol} \%$ of TBAB (entries 2-5, Table S3). Notably in this case the nature of the substituents on the [OSSO] ligands has a more pronounced effect on the catalytic activity with respect to the cycloaddition reaction. Indeed, the methyl-substituted complex 3 leads only to the formation of traces of polymer after $2 \mathrm{~h}$ (entry 4, Table S3), while a conversion of $40 \%$ was obtained in the presence of the more sterically encumbered cumylsubstituted complex 2 (entry 3, Table S3), with a TOF of $200 \mathrm{~h}^{-1}$. A further increase of the steric demand introducing trityl groups in the $R_{1}$ positions, or reducing the flexibility of the ligand, changing the ethyl bridge with a cyclohexyl moiety, negatively affects the catalytic performance with respect to catalyst 2 (entries 2 and 5, Table S3). The effect of cocatalyst type and loading on the catalytic activity of complex $\mathbf{2}$ was also investigated (entries 6-18, Table S3). It is worth noting that in the case of the copolymerization reaction, the catalyst, although with lower activity, is active even in the absence of any cocatalyst giving polycyclohexene oxide with a low content of carbonate linkages (7\%, entry 7, Table S3). Moreover, TBAC vis-à-vis $\mathrm{TBAB}$ was found to be the most effective cocatalyst, reaching $34 \%$ of conversion in $1 \mathrm{~h}$ and a TOF equal to $340 \mathrm{~h}^{-1}$ (entry 16, Table S3). Such a difference is often observed for the copolymerization reaction, and is commonly attributed to the different behaviors of the chloride anion with respect to the bromide as a leaving group. ${ }^{6}$ Halving the amount of TBAC with respect to 2 halves the catalytic activity, but it does not affect the polymer composition (entry 15, Table S3), while using 2 equiv of TBAC with respect to iron resulted only in a moderate increase of the catalytic activity, reaching a TOF equal to $400 \mathrm{~h}^{-1}$. The variation of the catalytic activity of 2 with respect to the temperature, in the range from 40 to $100{ }^{\circ} \mathrm{C}$, was also monitored (entries 19-21, Table S3). When the temperature was lower than $60{ }^{\circ} \mathrm{C}$, the conversion was negligible. Raising the temperature to $100{ }^{\circ} \mathrm{C}$ increases the catalytic activity by about the $20 \%$. The effect of the carbon dioxide pressure on the copolymerization process was investigated. When the reaction was performed at 5 bar, the catalytic activity was slightly lower than that recorded at 10 bar. Remarkably, good catalytic activity was observed even at 1 bar of $\mathrm{CO}_{2}$ pressure (TOF $=165 \mathrm{~h}^{-1}$, entry 22, Table S3), without variations in the polymer composition. Interestingly, the TOF observed at 20 bar was similar to that of the experiment conducted at 1 bar (entry 24, Table S3); however, significantly lower molecular weight was obtained in the first case.

At this point, the catalytic performances of $1-4$ were compared determining the conversion of $5 \mathrm{~m}$ in $6 \mathrm{~m}$ after $1 \mathrm{~h}$, at $80{ }^{\circ} \mathrm{C}, 10$ bar of $\mathrm{CO}_{2}$ pressure, $0.1 \mathrm{~mol} \%$ of iron, and $0.1 \mathrm{~mol}$ $\%$ of TBAC (entries 1-4, Table 2). Only for complex 3 , the reaction time was fixed at $6 \mathrm{~h}$ to obtain a suitable polymer sample for further analysis and to verify the selectivity of the reaction (entry 3 , Table 2 ). Under these optimized reaction conditions, the trend of the catalytic activities observed by using TBAB as cocatalyst was confirmed, with complex 2 being the most effective catalyst of the series (entry 2, Table 2).

In all cases a bimodal distribution of the molecular weights was obtained. Such behavior is commonly observed for this kind of polymerization and was typically attributed to the 
Table 2. $5 \mathrm{~m} / \mathrm{CO}_{2}$ Copolymerization Using $1-4^{a}$

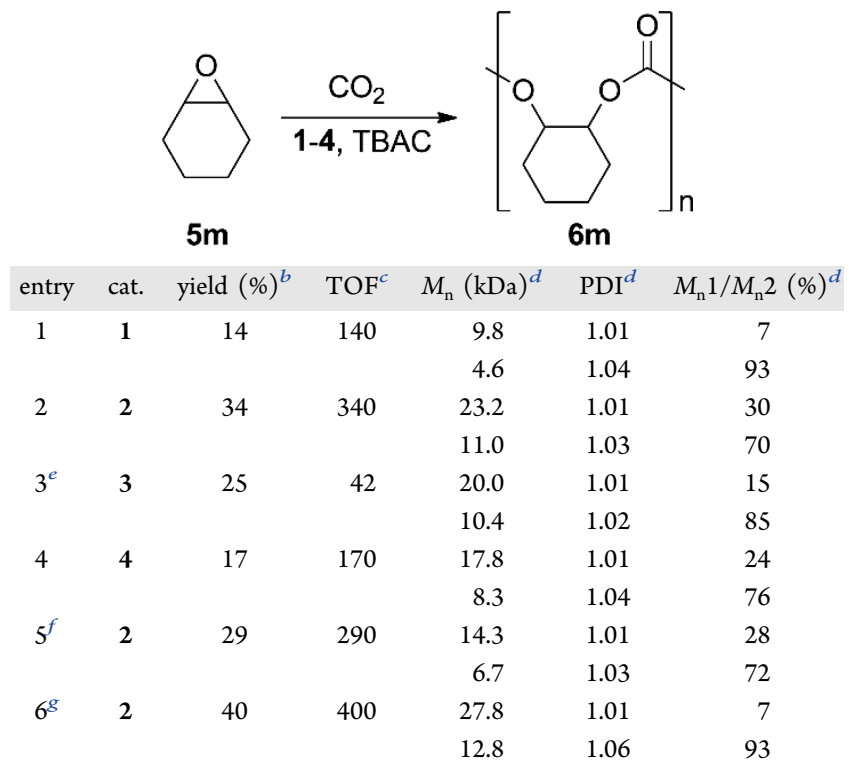

${ }^{a}$ Reaction conditions: $5 \mathrm{~m}=5.93 \times 10^{-2} \mathrm{~mol}$; catalyst $=0.1 \mathrm{~mol} \%$; TBAC $=0.1 \mathrm{~mol} \% ; T=80^{\circ} \mathrm{C} ; P\left(\mathrm{CO}_{2}\right)=10 \mathrm{bar}$; reaction time $=1$ h; neat. ${ }^{b}$ Gravimetic. Carbonate linkages always $>99 \%$. ${ }^{c}$ Turnover frequency (yield $\cdot 0.01 \cdot \mathrm{mol}_{\text {Catalyst }}{ }^{-1} \cdot$ reaction time ${ }^{-1}$ ). ${ }^{d}$ Determined by gel permeation chromatography at $30{ }^{\circ} \mathrm{C}$ in THF with respect to polystyrene standards. ${ }^{e}$ Reaction time $=6 \mathrm{~h} .{ }^{f_{\mathrm{H}_{2}} \mathrm{O}=0.1 \mathrm{~mol} \% .}{ }^{g} 5 \mathrm{~m}$ was distilled twice over $\mathrm{CaH}_{2}$ prior to use.

presence of traces of water in the reaction system. ${ }^{13 \mathrm{~b}, 23 \mathrm{c}} \mathrm{To}$ verify this hypothesis, the copolymerization of $\mathbf{5 m}$ with $\mathrm{CO}_{2}$ in the presence of 2 was repeated under two different reaction conditions: in the first case, 1 equiv of water with respect to iron was added to the reaction mixture; in the second case, the amount of water in the system was minimized by distilling the epoxide twice over $\mathrm{CaH}_{2}$ (entries 5 and 6, Table 2). In the presence of water, the catalytic system is still capable of promoting the copolymerization; however, lower molecular weights were obtained. In contrast, minimizing the water content in the system reflects favorably on both catalytic activity and molecular weights distribution. Indeed, the TOF rises from 340 to $400 \mathrm{~h}^{-1}$ and an almost unimodal and narrow distribution was obtained. To the best of our knowledge, this is the highest activity reported so far for an iron-based catalyst for the copolymerization of $\mathrm{CO}_{2}$ and $\mathbf{5 m}$. This is also beneficial for the thermal properties of the final product. In effect, the glass transition temperature $\left(T_{\mathrm{g}}\right)$ increases from 91 to $118^{\circ} \mathrm{C}$ as a consequence of the increased molecular weight of the polycarbonate (Figure S26).

To better understand the reaction mechanism, a detailed kinetic investigation was performed for the formation of $6 \mathbf{b}$ using the system $4 / \mathrm{TBAB}$ and for the $6 \mathrm{~m}$ formation using the system 2 /TBAC, by means of online attenuated total reflection infrared (ATR-IR) measurements.

Kinetic Study for $\mathbf{6 b}$ Formation. The formation of $\mathbf{6 b}$ in the presence of $4 / \mathrm{TBAB}$ as the catalytic system was investigated, using a $\mathbf{5 b} / \mathrm{CH}_{2} \mathrm{Cl}_{2}$ solution as the reaction medium to guarantee the homogeneity of the system during the experiments. The general kinetic equation for the reaction of $\mathrm{CO}_{2}$ with $\mathbf{5 b}$ can be written as follows:

$$
v=k[\mathbf{5 b}]^{\mathrm{a}}\left[\mathrm{CO}_{2}\right]^{\mathrm{b}}[\mathbf{4}]^{\mathrm{c}}[\mathrm{TBAB}]^{\mathrm{d}}
$$

At first, the reaction order with respect to 4 was determined by performing a series of experiments varying the concentration of 4 in the range from 4.8 to $28.6 \mathrm{mM}$, keeping the concentration of TBAB constant at $28.6 \mathrm{mM}$. The double logarithmic plot of the initial rate $\left(v_{0}\right)$ versus the concentration of the complex is shown in Figure 2a. It emerges that the rate of the reaction
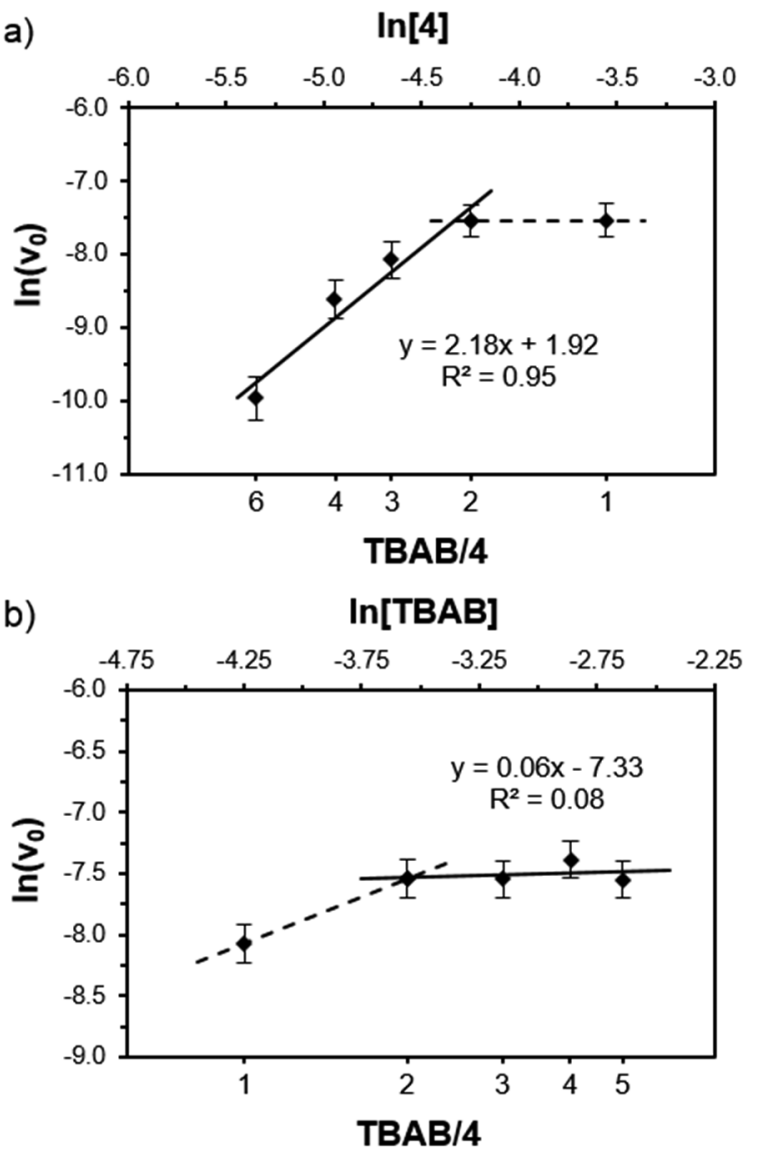

Figure 2. Plot of $\ln \left(v_{0}\right)$ for the formation of $6 \mathbf{b}$ versus (a) $\ln [4]$ and (b) $\ln [\mathrm{TBAB}]$. The $\mathrm{TBAB} / 4$ molar ratio is reported on the bottom axes.

follows a second-order dependence in 4. However, the dependence on the catalyst concentration is valid only in the presence of an excess of the cocatalyst, namely, when the $\mathrm{TBAB} / 4$ molar ratio is equal to or more than 2 . This finding is in accordance with the observation that the presence of the cocatalyst is essential for the expression of the catalytic activity. An analogous set of experiments was performed to study the dependence with respect to $\mathrm{TBAB}$, varying the concentration of $\mathrm{TBAB}$ in the range from 14.3 to $71.5 \mathrm{mM}$, keeping the concentration of 4 constant at $14.3 \mathrm{mM}$. The double logarithmic plot of the initial rate versus the concentration of the cocatalyst is shown in Figure 2b. Compared to 4, specular behavior was observed in this case. Indeed, the reaction rate increases until the TBAB is in excess with respect to iron, while a zero-order dependence was observed when the $\mathrm{TBAB} / 4$ molar ratio is equal to or higher than 2 . The results described above suggest that complex 4 reacts with $\mathrm{TBAB}$, forming a new species that is involved in the reaction mechanism. Similar behavior was recently described by North and co-workers in the case of a chromium(III) salophen system. ${ }^{18 \mathrm{e}}$ In that case, the reaction order with respect to the concentration of the 
chromium complex was found to be 0 when the concentration of $\mathrm{Cr}(\mathrm{III})$ was higher than that of TBAB, and 1 when it was lower. Such behavior was explained showing that the native complex reacts with $\mathrm{TBAB}$, forming a new species [Cr(salophen) $\left.\mathrm{Br}_{2}\right]^{-}$, that was claimed to be the real catalyst. To verify the occurrence of a similar reaction, the UV-vis spectra of $\mathrm{CH}_{2} \mathrm{Cl}_{2}$ solutions of 4 in the presence of different amounts of $\mathrm{TBAB}$ have been recorded (Figure 3 ).

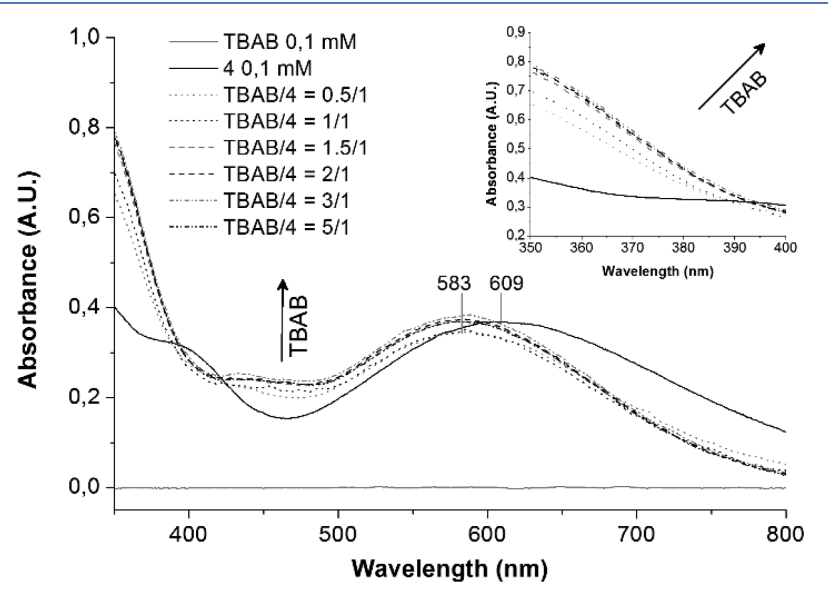

Figure 3. $\mathrm{UV}$-vis spectra of complex 4 in $\mathrm{CH}_{2} \mathrm{Cl}_{2}$ solution before and after the addition of $\mathrm{TBAB}$ (from 0.5 to 5 equiv with respect to $\mathrm{Fe}(\mathrm{III})$ ). The TBAB spectrum is reported on the bottom for comparison. Inset: magnification of the spectra from 350 to $400 \mathrm{~nm}$.

After the addition of only 0.5 equiv of TBAB, the spectrum profile completely changes. For example, the maximum of absorbance at $610 \mathrm{~nm}$ undergoes a blue shift to $583 \mathrm{~nm}$. It is worth noting that the absorbance intensity rises with the addition of more $\mathrm{TBAB}$, until the $\mathrm{TBAB} / 4$ molar ratio is equal to 2 (see the inset of Figure 3). At this value the intensity does not change anymore, even in the presence of 5 equiv of TBAB. From this result, it appears that the reaction seams to proceed until 2 equiv of $\mathrm{TBAB}$ with respect to iron are added to the solution. This can be explained with the formation of a new iron-containing anionic species $\left[4-\mathrm{Br}_{2}\right]^{-}$in which the chlorine atom is substituted with the bromine coming from $\mathrm{TBAB}$, and consequently further reaction is not possible (Figure 4).

The reaction order with respect to $\mathbf{5 b}$ was determined by performing a series of experiments with different concentrations of the epoxide. The double logarithmic plot of $v_{0}$ with respect to the concentration of $\mathbf{5} \mathbf{b}$ gives a first-order dependence (Figure 5a). With constant epoxide concentration,

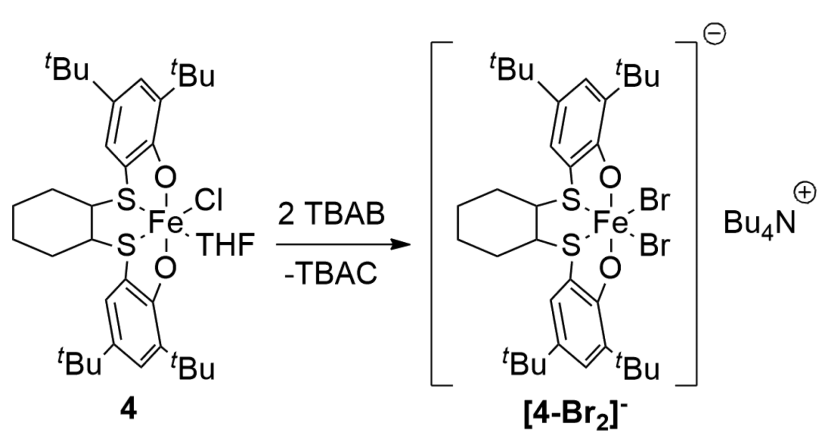

Figure 4. Formation of the anionic species $\left[4-\mathrm{Br}_{2}\right]^{-}$in the presence of TBAB. the $\mathrm{CO}_{2}$ pressure was changed in the range from 2 to 8.5 bar, and the reaction order with respect to $\mathrm{CO}_{2}$ was found to be 0 (Figure 5b).

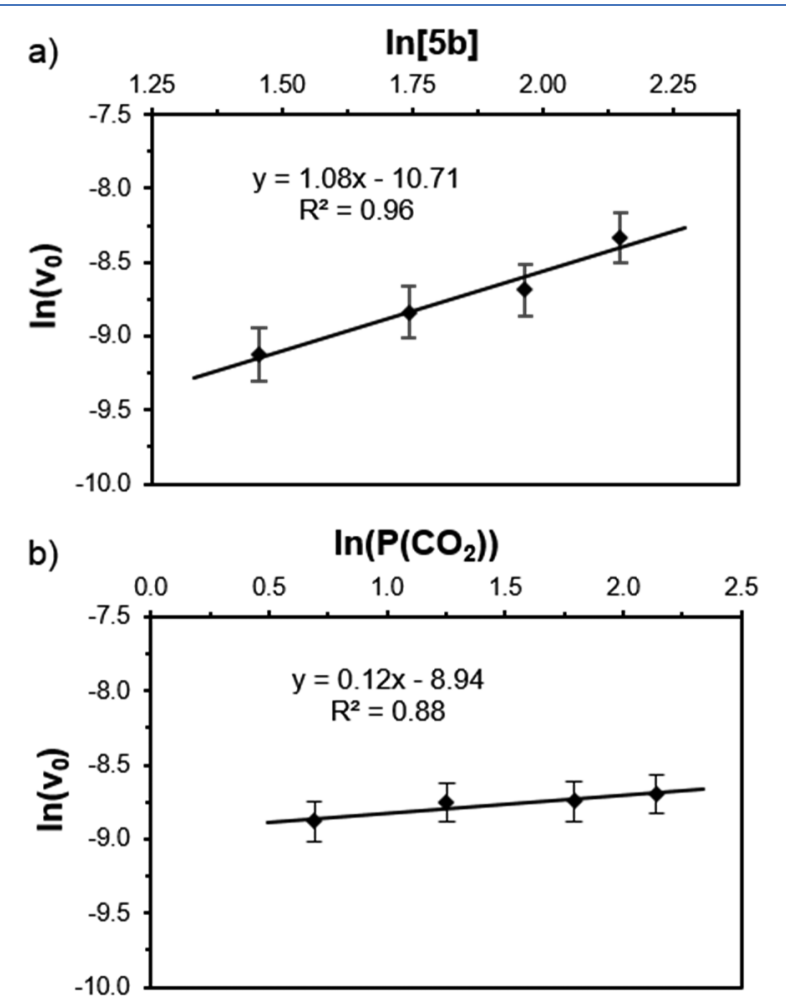

Figure 5. Plot of $\ln \left(v_{0}\right)$ for the formation of $\mathbf{6 b}$ versus (a) $\ln [\mathbf{5 b}]$ and (b) $\ln \left(P\left(\mathrm{CO}_{2}\right)\right)$.

On the basis of the Eyring equation, the thermodynamic parameters for the reaction can be determined by plotting the $\ln (k / T)$ versus $1 / T$. The reaction of $\mathbf{5 b}$ with $\mathrm{CO}_{2}$ was conducted, under the same reaction conditions, at different temperatures from 30 to $70{ }^{\circ} \mathrm{C}$, and the Eyring plot is shown in Figure S35. We found the following results: $\Delta H^{\ddagger}=8.4 \pm 0.7$ $\mathrm{kcal} / \mathrm{mol}, \Delta S^{\ddagger}=-33 \mathrm{cal} /(\mathrm{mol} \cdot \mathrm{K})$ and $\Delta G_{323}^{\ddagger}=19.0 \pm 1.7$ $\mathrm{kcal} / \mathrm{mol}$.

Finally, in the presence of an excess of the cocatalyst, the kinetic equation for the formation of $\mathbf{6 b}$ can be written as follows:

$$
v=k[\mathbf{5 b}][\mathbf{4}]^{2}
$$

From all the data described above, it is reasonable to conclude that the ring opening of the epoxy ring is the rate-limiting step of the reaction and that, in spite of the mononuclear nature of the [OSSO]-Fe(III) complex, the second-order dependence with respect to the concentration of 4 shows that two metal centers are involved in this step.

Kinetic Study for $6 \mathrm{~m}$ Formation. The formation of $6 \mathrm{~m}$ in the presence of $2 / \mathrm{TBAC}$ as the catalytic system was investigated, using a $5 \mathrm{~m} /$ toluene solution as the reaction medium to guarantee the homogeneity of the system during the experiments. The general kinetic equation for the chain growth of $6 \mathrm{~m}$ in the copolymerization of $\mathrm{CO}_{2}$ with $5 \mathrm{~m}$ can be written as follows:

$$
v=k[\mathbf{5 m}]^{\mathrm{a}}\left[\mathrm{CO}_{2}\right]^{\mathrm{b}}[\mathbf{2}]^{\mathrm{c}}[\mathrm{TBAC}]^{\mathrm{d}}
$$


At first, the reaction order with respect to 2 was determined by performing a series of experiments varying the concentration of 2 in the range from 3.6 to $18.2 \mathrm{mM}$, keeping the concentration of TBAC constant at $9.1 \mathrm{mM}$. The double logarithmic plot of the initial rate versus the concentration of the catalyst is shown in Figure 6a. Different from the case of $\mathbf{5 b}$, the reaction order

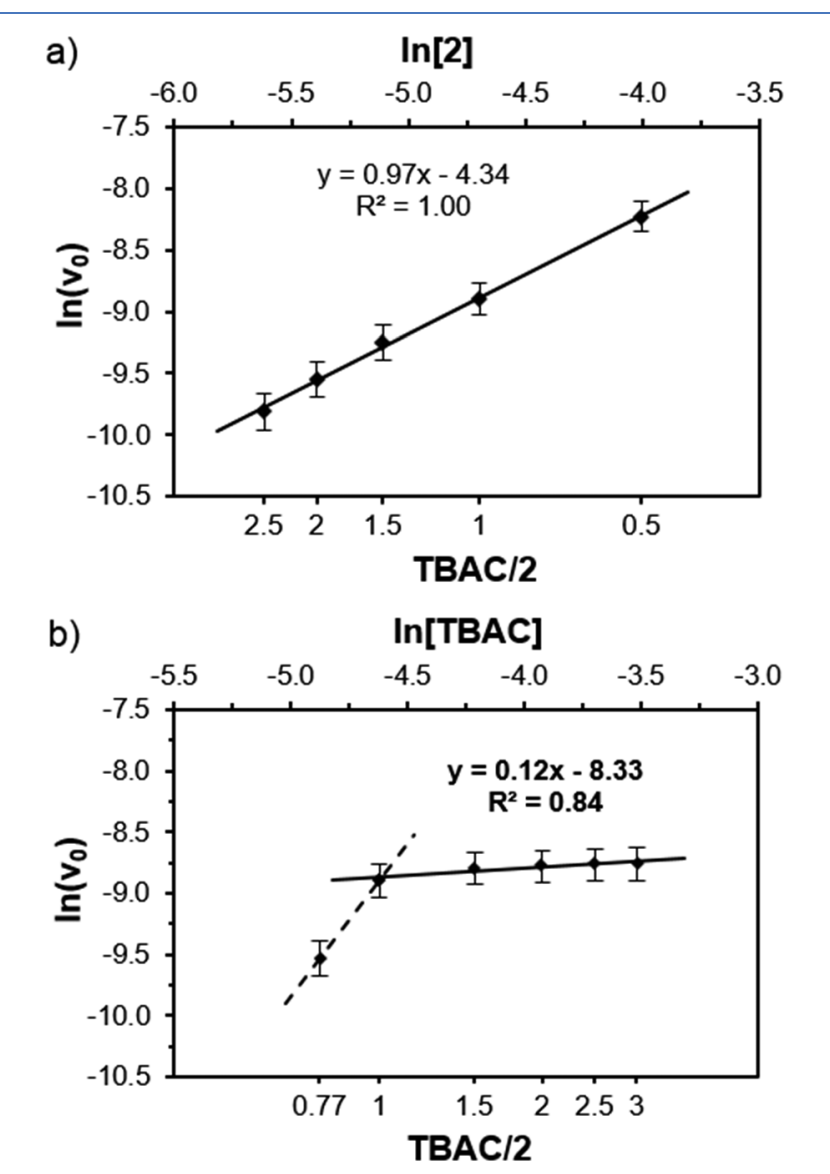

Figure 6. Plot of $\ln \left(v_{0}\right)$ for the formation of $6 \mathrm{~m}$ versus (a) $\ln [2]$ and (b) $\ln [\mathrm{TBAB}]$. The TBAC $/ 2$ molar ratio is reported on the bottom axes.

with respect to the complex 2 was found to be 1 . Moreover, the slope of the line does not change by varying the TBAC/2 ratio, even in the case in which the cocatalyst is substoichiometric with respect to 2 . This is in agreement with the observation that the iron complex is able to catalyze the reaction even in the absence of an exogenous nucleophile.

An analogous set of experiments was performed to study the dependence with respect to TBAC, varying the concentration of TBAC in the range from 7.6 to $29.7 \mathrm{mM}$, keeping the concentration of 2 constant at $9.8 \mathrm{mM}$. The double logarithmic plot of the initial rate versus the concentration of the cocatalyst is shown in Figure 6b. A zero-order dependence was found in this case. However, the reaction rate depends on the $[\mathrm{TBAC}]$ when the iron catalyst is in excess. That dependence indicates that the addition of TBAC results in a better activation of the complex, with the concentration of the activated catalyst increasing until the $1 / 1$ molar ratio. The reaction order with respect to $\mathbf{5 m}$ was determined by performing a series of experiments with different concentrations of the comonomer.

The double logarithmic plot of the initial rate with respect to the concentration of the epoxide gives a first-order dependence with respect to $\mathbf{5 m}$ (Figure $7 \mathrm{a}$ ). With constant $\mathbf{5 m}$ concentration, the carbon dioxide pressure was changed in the range from 6 to $9 \mathrm{bar}$ and the reaction order with respect to $\mathrm{CO}_{2}$ was found to be 0 (Figure $7 \mathrm{~b}$ ).
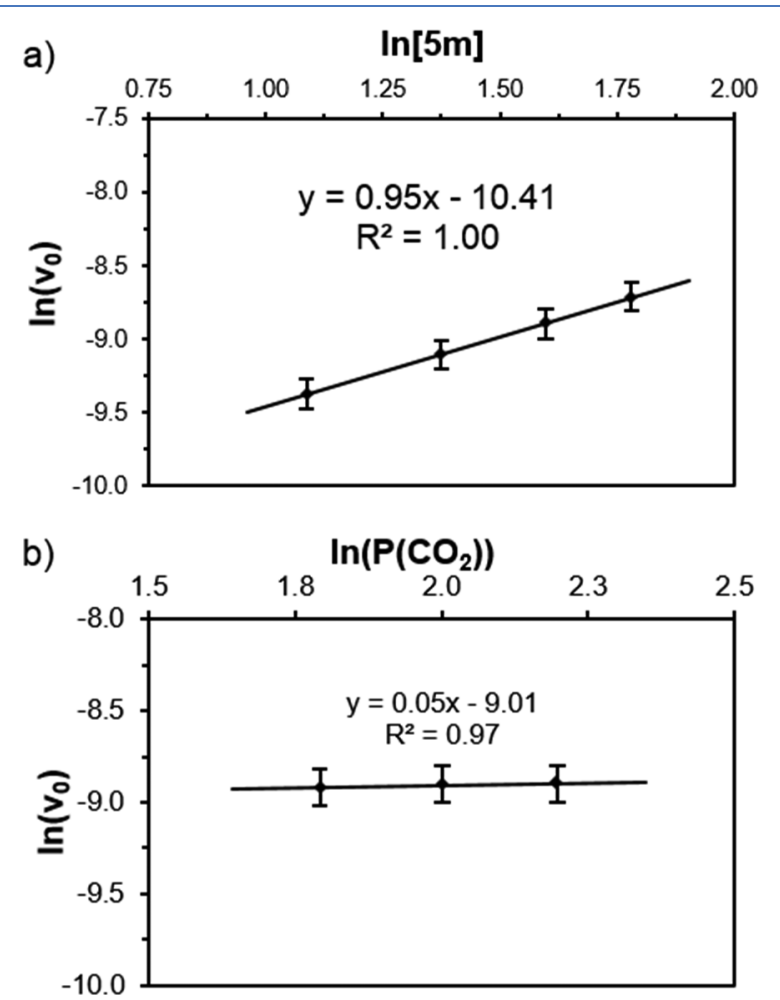

Figure 7. Plot of $\ln \left(v_{0}\right)$ for the formation of $6 \mathrm{~m}$ versus (a) $\ln [5 \mathrm{~m}]$ and (b) $\ln \left(P\left(\mathrm{CO}_{2}\right)\right)$.

The copolymerization reaction of $5 \mathrm{~m}$ with $\mathrm{CO}_{2}$ was conducted, under the same reaction conditions, at different temperatures in the range from 60 to $90{ }^{\circ} \mathrm{C}$, and the Eyring plot is shown in Figure S42. Using this data, we found the following results: $\Delta H^{\ddagger}=11.9 \pm 0.3 \mathrm{kcal} / \mathrm{mol}, \Delta S^{\ddagger}=-36 \pm 2$ $\mathrm{cal} /(\mathrm{mol} \cdot \mathrm{K})$, and $\Delta G_{353}^{\ddagger}=24.4 \pm 1.1 \mathrm{kcal} / \mathrm{mol}$.

Finally, the kinetic equation for the propagation step of the copolymerization of $\mathbf{5 m}$ with $\mathrm{CO}_{2}$ can be written as follows:

$$
v=k[5 \mathbf{m}][2]
$$

Analogous to the formation of $\mathbf{6 b}$, also in this case it is reasonable to assume that the rate-limiting step involves the ring opening of the epoxide by the growing polymer chain. Consequently, an excess of cocatalyst is not needed to obtain the maximum catalytic activity, different from what is observed in the case of the COCs formation. The reason lies in the fact that, in the case of the copolymerization, the TBAC is involved only during the initiation step, that is, the ring opening of the first epoxide ring. Indeed, during the propagation reaction, the insertion of the epoxide happens in the $\mathrm{Fe}$-carbonate bond.

The divergence in the cyclic carbonate or the polycarbonate formation on the basis of the reaction conditions has been reported for different catalytic systems. In particular, the temperature dependence of the product mixture composition in the case of $\mathbf{5 b}$ and $\mathbf{5 m}$ was investigated by Coates and coworkers, ${ }^{24}$ Darensbourg et al., ${ }^{18 a}$ and Williams and coworkers. ${ }^{13 \mathrm{~b}}$ In all these cases, both products were claimed to be derived from the same reaction mechanism in which the polycarbonate was identified as the kinetic product, favored at 


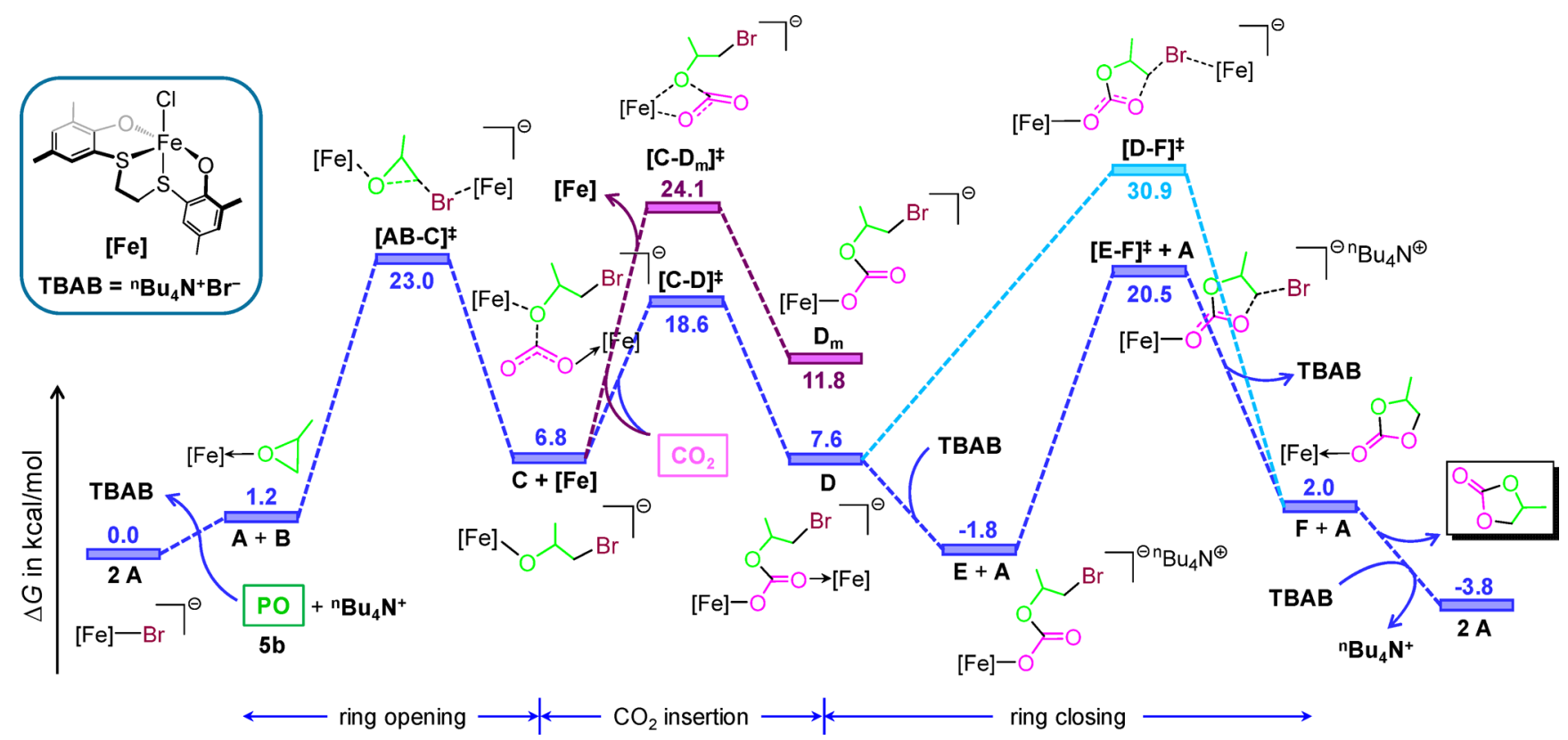

Figure 8. Computed energy profile for the cycloaddition of propylene oxide $(\mathbf{5 b})$ with $\mathrm{CO}_{2}$ catalyzed by species 3 . Free energies in solution at the $\mathrm{UM06}(\mathrm{PCM}) / \mathrm{SDD}(\mathrm{Fe}) / \mathrm{TZVPD}(\mathrm{Br}) / \mathrm{TZVP}(\mathrm{C}, \mathrm{H}, \mathrm{N}, \mathrm{O}, \mathrm{Cl}, \mathrm{S}) / / \mathrm{UBP} 86 / \mathrm{SDD}(\mathrm{Fe}) / \mathrm{SVP}(\mathrm{C}, \mathrm{H}, \mathrm{N}, \mathrm{O}, \mathrm{Cl}, \mathrm{S}, \mathrm{Br})$ level are displayed.

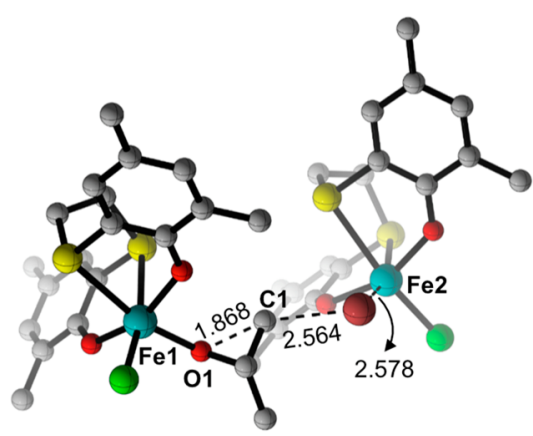

$[\mathrm{AB}-\mathrm{C}]^{\ddagger}$

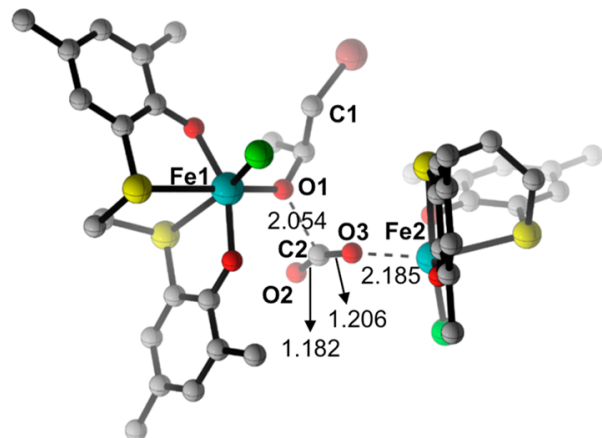

$[C-D]^{\ddagger}$

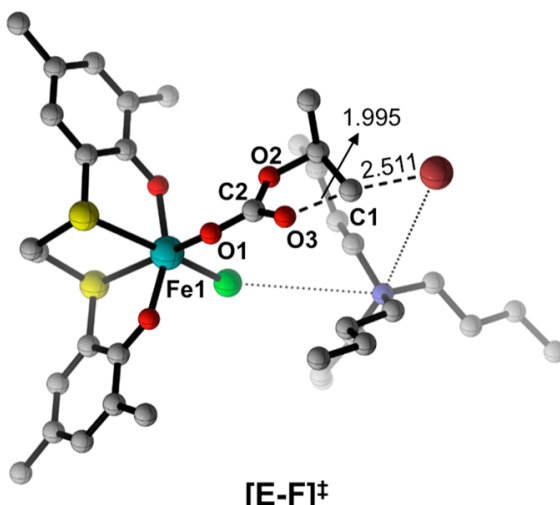

$[E-F]^{\ddagger}$

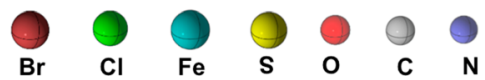

Figure 9. Optimized geometries of selected transition states. Hydrogen atoms are hidden for clarity.

low temperature, and the cyclic carbonate as the thermodynamic product, favored at high temperature. The key for the selective formation of the polycarbonate at low temperature was thus identified in the different activation energies between the propagation and the backbiting reaction.

In the case of the [OSSO]-Fe(III) complexes 1-4 discussed in this study, a direct comparison of the activation energies for a given epoxide between the cyclic and polymeric product is not possible because of the selective formation of only one product regardless of the reaction conditions employed, underlying that the observed selectivity is rather a consequence of the complete inhibition of the cyclization for the epoxide $5 \mathrm{~m}$.

Computational Study. DFT calculations were performed to obtain insight into the mechanism for Fe-catalyzed coupling of $\mathrm{CO}_{2}$ with epoxides. The [OSSO]-Fe(III) complex 3 was selected as catalyst for the calculations. Considering that the aforementioned experimental studies showed that up to 2 equiv of $\mathrm{TBAB}$ can react with the iron precatalyst (Figures $2-4)$, we started by exploring the substitution of $\mathrm{MeCN}$ of precatalyst 3 by a $\mathrm{Br}^{-}$of $\mathrm{TBAB}$, leading to the $\mathrm{Fe}-\mathrm{Br}$ intermediate $A$ (Figure 8) with an energy gain of $4.2 \mathrm{kcal} / \mathrm{mol}$ (Scheme S1). On the basis of this, we assumed complex $\mathbf{A}$ as the starting point of the catalytic cycle. The overall pathway (Figure 8) is divided into three sections: (i) ring opening of $\mathbf{5 b}$; (ii) $\mathrm{CO}_{2}$ insertion; (iii) ring closing to liberate the cyclic carbonate. Optimized geometries of selected transition states are shown in Figure 9. The reaction starts with the replacement of $\mathrm{Br}^{-}$in $\mathbf{A}$ by the substrate (5b) generating $\mathbf{B}$, a step endergonic by $1.2 \mathrm{kcal} / \mathrm{mol}$.

On the basis of the experimental evidence that the ring opening of $\mathbf{5 b}$ is second order in [Fe] (Figure 2a), the most reasonable explanation consistent with the experiments is the interaction of $\mathbf{A}$ and $\mathbf{B}$ via the bimetallic transition state $[\mathbf{A B}-$ $\mathbf{C}]^{\ddagger}$. This step requires the overcoming of a free energy span of $23.0 \mathrm{kcal} / \mathrm{mol}$ from two A, and leads to the formation of the intermediate $\mathrm{C}$, presenting a $\mathrm{Fe}-\mathrm{O} \sigma$-bond, and liberation of a Fe complex with a vacancy on the Fe center. The calculated energy span is in good agreement with the experimental activation energy, $19.0 \pm 1.7 \mathrm{kcal} / \mathrm{mol}$, estimated from the 

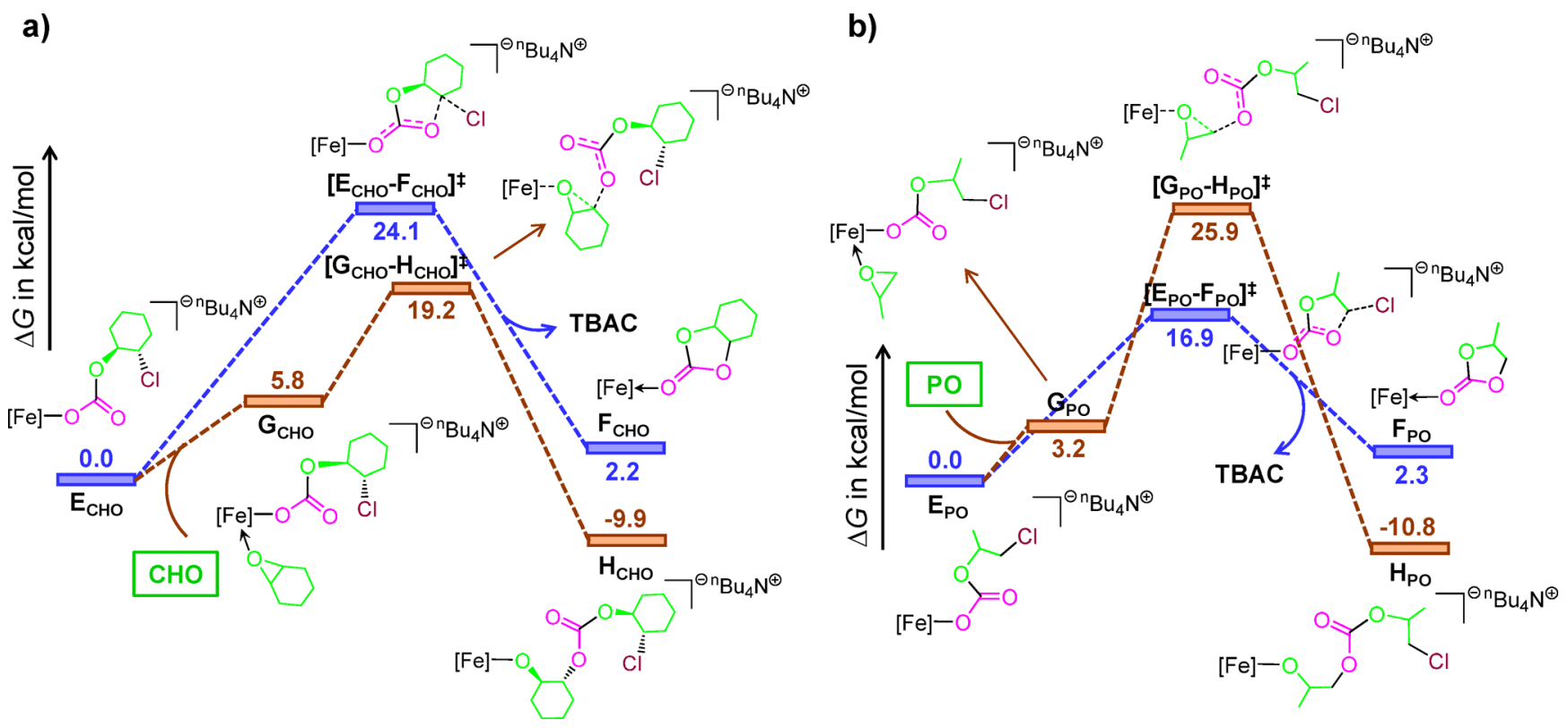

Figure 10. Energy profile for the competitive ring closing vs copolymerization steps with $\mathbf{5 m}(\mathrm{a})$ and $\mathbf{5 b}$ (b). Free energies in solution at the $\mathrm{UM06}(\mathrm{PCM}) / \mathrm{SDD}(\mathrm{Fe}) / \mathrm{TZVPD}(\mathrm{Br}) / \mathrm{TZVP}(\mathrm{C}, \mathrm{H}, \mathrm{N}, \mathrm{O}, \mathrm{Cl}, \mathrm{S}) / / \mathrm{UBP} 86 / \mathrm{SDD}(\mathrm{Fe}) / \mathrm{SVP}(\mathrm{C}, \mathrm{H}, \mathrm{N}, \mathrm{O}, \mathrm{Cl}, \mathrm{S}, \mathrm{Br})$ level are displayed.

Eyring plot of Figure S35. Nevertheless, considering that the $\mathrm{Fe}$-epoxide complex $\mathbf{B}$ is only $1.2 \mathrm{kcal} / \mathrm{mol}$ above $\mathbf{A}$, and the large excess of $\mathbf{5 b}$ relative to $\mathrm{Fe}$ and $\mathrm{TBAB}$ (Table 1 and Scheme 3), it is reasonable to assume the presence of a significant amount of $\mathbf{B}$ in solution. With use of a mixture of $\mathbf{A}$ $+\mathbf{B}$ as reference structure, the calculated energy barrier to transition state $[\mathbf{A B}-\mathbf{C}]^{*}$ is $21.8 \mathrm{kcal} / \mathrm{mol}$, which is in better agreement with the experimental value, further supporting the mechanistic scenario we developed for the opening of $\mathbf{5} \mathbf{b}$.

The next step corresponds to insertion of $\mathrm{CO}_{2}$ into the $\mathrm{Fe}-$ $\mathrm{O}$ bond of the intermediate $\mathrm{C}$ to generate the hemicarbonate D. As no experiment is guiding the DFT calculations, we investigated both monometallic (purple) and bimetallic (blue) pathways. The bimetallic route, ${ }^{25}$ via transition state $[\mathbf{C}-\mathbf{D}]^{\sharp}$, is more facile because of a lower activation barrier from $\mathbf{C}$ $\left(\Delta G^{\ddagger}=11.8 \mathrm{kcal} / \mathrm{mol}\right)$ compared to that from the monometallic route $\left(\Delta G^{\ddagger}=17.3 \mathrm{kcal} / \mathrm{mol}\right)$.

This can be related to the greater electrophilic nature of the $\mathrm{C}$ atom of the $\mathrm{Fe}$-activated $\mathrm{CO}_{2}$ in the transition state $[\mathrm{C}-\mathrm{D}]^{\text {* }}$ $\left(q_{\mathrm{C} 2}=1.092 \mathrm{e}\right)$, which facilitates the insertion of $\mathrm{CO}_{2}$ with respect to the monometallic pathway, with a less electrophilic $\mathrm{CO}_{2}$ in transition state $\left[\mathbf{C}-\mathbf{D}_{\mathrm{m}}\right]^{\ddagger}\left(q_{\mathrm{C} 2}=0.992 e\right)$. Consistent with the literature, geometry optimization of the transition state $\left[\mathbf{C}-\mathbf{D}_{\mathrm{m}}\right]^{\ddagger}$ on the products side results in a kinetic intermediate with the chain end coordinated to the Fe center activating $\mathrm{CO}_{2}$ (chain-shuttling mechanism), ${ }^{7 \mathrm{a}, 13 \mathrm{~b}, \mathrm{c}, 25}$ which further relaxes on the more stable hemicarbonate $\mathbf{D}$, with the chain end stabilized by both $\mathrm{Fe}$ centers. The resulting hemicarbonate along the bimetallic route, $\mathbf{D}$, is also more stable (by $4.2 \mathrm{kcal} / \mathrm{mol}$ ) than the congener $\mathrm{D}_{\mathrm{m}}$ along the monometallic route.

From intermediate $\mathbf{D}$ we modeled the final ring-closing step to achieve the desired cyclic carbonate, and we again tested different possibilities. The first was direct ring closing from intermediate $\mathbf{D}$. It occurs via transition state $[\mathbf{D}-\mathbf{F}]^{*}$ and a total energy span of $30.9 \mathrm{kcal} / \mathrm{mol}$ from the reference two A complexes. This energy span is too high to be consistent with the reaction condition used, so we searched for alternative pathways. We thus reacted $\mathrm{D}$ with a TBAB molecule to release the neutral monomeric Fe complex $\mathbf{E}$ with regeneration of $\mathbf{A}$. This is an exergonic step with release of $9.4 \mathrm{kcal} / \mathrm{mol}$. Ring closing from $\mathbf{E}$ via transition state $[\mathbf{E}-\mathbf{F}]^{*}$, with an energy span of $22.3 \mathrm{kcal} / \mathrm{mol}$, is instead consistent with the experimental conditions. In the resulting intermediate $\mathbf{F}$ the formed cyclic carbonate is coordinated to Fe. Displacement of the cyclic carbonate by a TBAB molecule closes the catalytic cycle by regenerating the second starting species $\mathbf{A}$. The computed energy profile reveals that ring opening of $\mathbf{5} \mathbf{b}$ is the ratedetermining step, and that $\mathrm{TBAB}$ and $\mathrm{CO}_{2}$ are not involved in the rate-controlling step. Finally, the experimental first-order kinetics with respect to the $\mathbf{5 b}$ concentration is also justified by the proposed mechanism.

The three fundamental transition states along the reaction pathway, $[\mathbf{A B}-\mathbf{C}]^{\ddagger},[\mathbf{C}-\mathbf{D}]^{\ddagger}$, and $[\mathbf{E}-\mathbf{F}]^{\ddagger}$, are shown in Figure 9. They exhibit breaking and forming bond distances comparable to those calculated for a bimetallic Fe(III) catalyst, supported by polydentate thiother-phenolate ligand. ${ }^{17}$ In these polydentate thiother-phenolate bimetallic catalysts the $\mathrm{CO}_{2}$ insertion step occurred on a single metal center, as the orientation of the breaking $\mathrm{Fe}-\mathrm{O}$ bond on one site, and the forming $\mathrm{Fe}-\mathrm{CO}_{2}$ bond on the other site (nearly syn oriented) did not allow for an optimal interaction between the molecular orbitals on the reacting atoms when two metal centers were involved. ${ }^{17}$ Differently, the monometallic catalysts considered here allow for an optimal orientation of the reacting groups because of the almost anti orientation of the breaking $\mathrm{Fe}-\mathrm{O}$ and forming $\mathrm{Fe}-\mathrm{CO}_{2}$ bonds in transition state $[\mathrm{C}-\mathrm{D}]^{\mathrm{F}}$ (Figure 9). On the other hand, the higher $\mathrm{Fe}$-coordination environment in the bimetallic $\mathrm{Fe}$ catalyst results in an easier ring-closing step, ${ }^{17}$ compared to the systems described in this work.

Having clarified the mechanism for the coupling of $\mathbf{5 b}$ and $\mathrm{CO}_{2}$ to a cyclic carbonate, we investigated the competition for cyclic carbonate formation versus copolymer formation when $\mathbf{5 m}$ is the epoxide. On the basis of the mechanism shown in Figure 8, $\mathbf{E}$ is the key intermediate from which another epoxide 
will insert into the $\mathrm{Fe}-\mathrm{O}$ bond within a copolymerization process, or ring closing to cyclic carbonate will start. We have modeled these two competitive steps following the experimental conditions, that is, in the presence of TBAC with toluene as the solvent. Consistent with the experiments, the calculated energetics (Figure 10a) indicates that $5 \mathrm{~m}$ insertion into the $\mathrm{Fe}-\mathrm{O}$ bond of $\mathbf{E}$, via transition state $\left[\mathbf{G}_{\mathrm{CHO}}-\mathbf{H}_{\mathrm{CHO}}\right]^{\frac{1}{*}}$ (dark orange line), is favored by $4.9 \mathrm{kcal} / \mathrm{mol}$ over ring closing via transition state $\left[\mathbf{E}_{\mathrm{CHO}}-\mathbf{F}_{\mathrm{CHO}}\right]^{*}$ (blue line).

For the sake of completeness, we also calculated the copolymerization step using $\mathbf{5 b}$ as the epoxide in the presence of TBAC (Figure 10b). According to calculations, coordination and insertion of a $\mathbf{5 b}$ molecule into the $\mathrm{Fe}-\mathrm{O}$ bond of $\mathbf{E}$, via transition state $\left[\mathbf{G}_{\mathbf{P O}}-\mathbf{H}_{\mathbf{P O}}\right]^{\ddagger}$, is disfavored by $9.0 \mathrm{kcal} / \mathrm{mol}$ relative to the ring-closing transition state $\left[\mathbf{E}_{\mathbf{P O}}-\mathbf{F}_{\mathbf{P O}}\right]^{+}$. Consistent with experiments, ring closure is thus favored with $\mathbf{5 b}$, while copolymerization is favored with $\mathbf{5 m}$. Comparison of Figures 8 and $10 \mathrm{~b}$ offers insight on the different role of the halide leaving group in the ring-closure step.

The energy barrier for ring closure with $\mathrm{Br}^{-}, 22.3 \mathrm{kcal} / \mathrm{mol}$ from $\mathrm{E}$, is calculated to be $5.4 \mathrm{kcal} / \mathrm{mol}$ higher than that calculated with $\mathrm{Cl}^{-}, 16.9 \mathrm{kcal} / \mathrm{mol}$. The higher barrier with $\mathrm{Br}^{-}$ can probably be related to poorer electrostatic stabilization of the larger bromide anion by the $\mathrm{Bu}_{4} \mathrm{~N}^{+}$cation and by the solvent.

To understand the different tendency of $\mathbf{5 m}$ and $\mathbf{5 b}$ to undergo copolymerization versus cyclic carbonate formation, we compared the thermochemistry of cyclic carbonates formation versus the epoxides structure (Figure 11). For better accuracy, thermochemistry was calculated according to the protocol described in ref 26 (see the Supporting Information, Scheme S2).

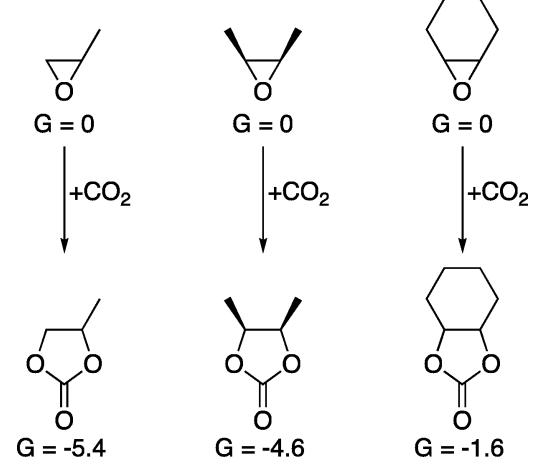

Figure 11. Thermochemistry of cyclic carbonate formation, in kcal/ mol.

According to our calculations, the conversion of $\mathbf{5 m}$ into the corresponding cyclic carbonate is $3.8 \mathrm{kcal} / \mathrm{mol}$ harder than conversion of $\mathbf{5 b}$, and $3.0 \mathrm{kcal} / \mathrm{mol}$ harder than conversion of $\mathbf{5 j}$. This trend is well in line with the tendency of $\mathbf{5 b}$ and $\mathbf{5 j}$ to undergo cyclic carbonate formation, and the tendency of $5 \mathrm{~m}$ to undergo copolymerization.

\section{CONCLUSION}

In conclusion, here we have reported on a new family of $\mathrm{Fe}(\mathrm{III})$ complexes (1-4) supported by bis-thioether-diphenolate [OSSO]-type ligands and their ability to promote the reaction of $\mathrm{CO}_{2}$ with oxiranes under very mild reaction conditions. These catalysts display excellent activity and selectivity for the formation of terminal and internal COCs starting from the corresponding epoxides. Intriguingly, in the case of cyclohexene oxide, the formation of the corresponding polycarbonate without the concomitant production of the cyclic carbonate, regardless the reaction temperature, was observed.

Moreover, kinetic measurements revealed a different reaction order for the iron complex in the cycloaddition and in the copolymerization reactions. As a matter of fact, in the case of the formation of propylene carbonate, a second order with respect to the $\mathrm{Fe}$ (III) concentration was found, while in the case of the poly(cyclohexene carbonate), a first order was observed, even though the ring opening of the epoxy ring was found to be the rate-limiting step in both cases (by the ironbonded halide in the first case and by the growing polymer chain in the second). It is the first time that a different reaction order between the two processes was clearly demonstrated using the same catalyst. In particular, the role of the Lewis acidic iron center in the activation of the epoxide ring was clearly pointed out.

DFT-based calculations identified a key monometallic Fecarbonate intermediate from which both cyclization and copolymerization can start. However, only in the case of cyclohexene oxide the energy barrier of the chain propagation step was found to be lower than that of the ring closing of the cyclic product.

These results show the potential of iron-based catalytic systems for these reactions under low $\mathrm{CO}_{2}$ pressure. Synergic experimental and computational investigation provided a detailed understanding of the overall mechanism, including the factors governing the selectivity in the formation of the cyclic versus the polymeric product. This knowledge can pave the way for the design of highly chemoselective catalysts, based on Earth-crust abundant metals such as iron.

\section{ASSOCIATED CONTENT}

\section{Supporting Information}

The Supporting Information is available free of charge on the ACS Publications website at DOI: 10.1021/acscatal.8b01695.

Details on the synthesis and characterization of complexes, crystal structure, reaction procedures, ATR FT-IR kinetic measurements, and DFT calculations (PDF)

\section{AUTHOR INFORMATION}

\section{Corresponding Authors}

*E-mail: rieger@tum.de.

*E-mail: luigi.cavallo@kaust.edu.sa.

*E-mail: ccapacchione@unisa.it.

ORCID

Francesco Della Monica: 0000-0001-6530-7351

Antonio Buonerba: 0000-0003-1101-3248

Alfonso Grassi: 0000-0002-2664-3114

Bernhard Rieger: 0000-0002-0023-884X

Luigi Cavallo: 0000-0002-1398-338X

Carmine Capacchione: 0000-0001-7254-8620

Author Contributions

${ }^{\#}$ F.D.M. and B.M. contributed equally.

\section{Notes}

The authors declare no competing financial interest. 


\section{ACKNOWLEDGMENTS}

Ministero dell'Istruzione dell'Università e della Ricerca (MIUR, Roma, Italy) and Università degli Studi di Salerno (FARB 2016-ORSA165551), the Centro di Tecnologie Integrate per la Salute (Project PONa3_00138) for the 600 $\mathrm{MHz}$ NMR instrumental time, Salvatore Impemba, Dr. Patrizia Oliva, Dr. Patrizia Iannece, Dr. Mariagrazia Napoli, and Dr. Ivano Immediata from University of Salerno for technical assistance are deeply acknowledged. C.C. thanks the Alexander von Humboldt foundation for financial support. L.C. and B.M. thank the King Abdullah University of Science and Technology for supporting this research.

\section{REFERENCES}

(1) (a) Carbon Dioxide Recovery and Utilization; Aresta, M., Ed.; Springer Science+Business Media: Dordrecht, 2003. (b) Carbon Dioxide Utilization: Closing the Carbon Cycle; Styring, P., Quadrelli, E. A., Armstrong, K., Eds.; Elsevier: Amsterdam, 2015. (c) Sanz-Pérez, E. S.; Murdock, C. R.; Didas, S. A.; Jones, C. W. Direct Capture of $\mathrm{CO}_{2}$ from Ambient Air. Chem. Rev. 2016, 116, 11840-11876. (d) Hunt, A. J.; Sin, E. H. K.; Marriott, R.; Clark, J. H. Generation, Capture, and Utilization of Industrial Carbon Dioxide. ChemSusChem 2010, 3, 306-322. (e) Martens, J. A.; Bogaerts, A.; De Kimpe, N.; Jacobs, P. A.; Marin, G. B.; Rabaey, K.; Saeys, M.; Verhelst, S. The Chemical Route to a Carbon Dioxide Neutral World. ChemSusChem 2017, 10, 1039-1055.

(2) (a) Carbon Dioxide as Chemical Feedstock; Aresta, M., Ed.; Wiley-VCH: Weinheim, 2010. (b) Aresta, M.; Dibenedetto, A.; Angelini, A. Catalysis for the Valorization of Exhaust Carbon: from $\mathrm{CO}_{2}$ to Chemicals, Materials, and Fuels. Technological Use of $\mathrm{CO}_{2}$. Chem. Rev. 2014, 114, 1709-1742. (c) Artz, J.; Müller, T. E.; Thenert, K.; Kleinekorte, J.; Meys, R.; Sternberg, A.; Bardow, A.; Leitner, W. Sustainable Conversion of Carbon Dioxide: An Integrated Review of Catalysis and Life Cycle Assessment. Chem. Rev. 2018, 118, 434-504.

(3) (a) von der Assen, N.; Jung, J.; Bardow, A. Life-Cycle Assessment of Carbon Dioxide Capture and Utilization: Avoiding the Pitfalls. Energy Environ. Sci. 2013, 6, 2721-2734. (b) Liu, Q.; Wu, L.; Jackstell, R.; Beller, M. Using Carbon Dioxide as a Building Block in Organic Synthesis. Nat. Commun. 2015, 6, 5933. (c) Reaction Mechanisms in Carbon Dioxide Conversion; Aresta, M., Dibenedetto, A., Quaranta, E., Eds.; Springer-Verlag: Berlin, 2016.

(4) (a) Centi, G.; Perathoner, S. Opportunities and Prospects in the Chemical Recycling of Carbon Dioxide to Fuels. Catal. Today 2009, 148, 191-205. (b) Qiao, J.; Liu, Y.; Hong, F.; Zhang, J. A Review of Catalysts for the Electroreduction of Carbon Dioxide to Produce Low-Carbon Fuels. Chem. Soc. Rev. 2014, 43, 631-675. (c) Li, Y.; Chan, S. H.; Sun, Q. Heterogeneous Catalytic Conversion of $\mathrm{CO}_{2}$ : a Comprehensive Theoretical Review. Nanoscale 2015, 7, 8663-8683. (d) Francke, R.; Schille, B.; Roemelt, M. Homogeneously Catalyzed Electroreduction of Carbon Dioxide-Methods, Mechanisms, and Catalysts. Chem. Rev. 2018, 118, 4631-4701.

(5) (a) Sakakura, T.; Choi, J.-C.; Yasuda, H. Transformation of Carbon Dioxide. Chem. Rev. 2007, 107, 2365-2387. (b) Martín, R.; Kleij, A. W. Myth or Reality? Fixation of Carbon Dioxide into Complex Organic Matter under Mild Conditions. ChemSusChem 2011, 4, 1259-1263. (c) Maeda, C.; Miyazaki, Y.; Ema, T. Recent Progress in Catalytic Conversions of Carbon Dioxide. Catal. Sci. Technol. 2014, 4, 1482-1497. (d) Song, Q.-W.; Zhou, Z.-H.; He, L.N. Efficient, Selective and Sustainable Catalysis of Carbon Dioxide. Green Chem. 2017, 19, 3707-3728.

(6) (a) Comerford, J. W.; Ingram, I. D. V.; North, M.; Wu, X. Sustainable Metal-Based Catalysts for the Synthesis of Cyclic Carbonates Containing Five-Membered Rings. Green Chem. 2015, 17, 1966-1987. (b) Martín, C.; Fiorani, G.; Kleij, A. W. Recent Advances in the Catalytic Preparation of Cyclic Organic Carbonates. ACS Catal. 2015, 5, 1353-1370. (c) Alves, M.; Grignard, B.; Mereau,
R.; Jerome, C.; Tassaing, T.; Detrembleur, C. Organocatalyzed Coupling of Carbon Dioxide with Epoxides for the Synthesis of Cyclic Carbonates: Catalyst Design and Mechanistic Studies. Catal. Sci. Technol. 2017, 7, 2651-2684. (d) Zhou, H.; Lu, X. Lewis Base- $\mathrm{CO}_{2}$ Adducts as organocatalysts for $\mathrm{CO}_{2}$ Transformation. Sci. China: Chem. 2017, 60, 904-911. (e) Shaikh, R. R.; Pornpraprom, S.; D’Elia, V. Catalytic Strategies for the Cycloaddition of Pure, Diluted, and Waste $\mathrm{CO}_{2}$ to Epoxides under Ambient Conditions. ACS Catal. 2018, 8, 419-450.

(7) (a) Coates, G. W.; Moore, D. R. Discrete Metal-Based Catalysts for the Copolymerization of $\mathrm{CO}_{2}$ and Epoxides: Discovery, Reactivity, Optimization, and Mechanism. Angew. Chem., Int. Ed. 2004, 43, 6618-6639. (b) Nozaki, K. Asymmetric Catalytic Synthesis of Polyketones and Polycarbonates. Pure Appl. Chem. 2004, 76, 541546. (c) Klaus, S.; Lehenmeier, M. W.; Anderson, C. E.; Rieger, B. Recent Advances in $\mathrm{CO}_{2}$ /Epoxide Copolymerization-New Strategies and Cooperative Mechanisms. Coord. Chem. Rev. 2011, 255, 14601479. (d) Kember, M. R.; Buchard, A.; Williams, C. K. Catalysts for $\mathrm{CO}_{2}$ /Epoxide Copolymerization. Chem. Commun. 2011, 47, 141163. (e) Childers, M. I.; Longo, J. M.; Van Zee, N. J.; LaPointe, A. M.; Coates, G. W. Stereoselective Epoxide Polymerization and Copolymerization. Chem. Rev. 2014, 114, 8129-8152. (f) Trott, G.; Saini, P. K.; Williams, C. K. Catalysts for $\mathrm{CO}_{2} /$ Epoxide Ring-Opening Copolymerization. Philos. Trans. R. Soc., A 2016, 374, 20150085. (g) Poland, S. J.; Darensbourg, D. J. A Quest for Polycarbonates Provided via Sustainable Epoxide $/ \mathrm{CO}_{2}$ Copolymerization Processes. Green Chem. 2017, 19, 4990-5011.

(8) (a) Schaffner, B.; Schaffner, F.; Verevkin, S. P.; Borner, A. Organic Carbonates as Solvents in Synthesis and Catalysis. Chem. Rev. 2010, 110, 4554-4581. (b) Sathish, M.; Sreeram, K. J.; Raghava Rao, J.; Unni Nair, B. Cyclic Carbonate: A Recyclable Medium for Zero Discharge Tanning. ACS Sustainable Chem. Eng. 2016, 4, 1032-1040. (c) Lawrenson, S.; North, M.; Peigneguy, F.; Routledge, A. Greener Solvents for Solid-Phase Synthesis. Green Chem. 2017, 19, 952-962. (d) Lawrenson, S. B.; Arav, R.; North, M. The Greening of Peptide Synthesis. Green Chem. 2017, 19, 1685-1691.

(9) Wei, X. L.; Xu, W.; Vijayakumar, M.; Cosimbescu, L.; Liu, T. B.; Sprenkle, V.; Wang, W. TEMPO-Based Catholyte for High-Energy Density Nonaqueous Redox Flow Batteries. Adv. Mater. 2014, 26, 7649-7653.

(10) (a) Beattie, C.; North, M.; Villuendas, P.; Young, C. Influence of Temperature and Pressure on Cyclic Carbonate Synthesis Catalyzed by Bimetallic Aluminum Complexes and Application to Overall syn-Bis-hydroxylation of Alkenes. J. Org. Chem. 2013, 78, 419-426. (b) Laserna, V.; Fiorani, G.; Whiteoak, C. J.; Martin, E.; Escudero-Adan, E.; Kleij, A. W. Carbon Dioxide as a Protecting Group: Highly Efficient and Selective Catalytic Access to Cyclic cisDiol Scaffolds. Angew. Chem., Int. Ed. 2014, 53, 10416-10419. (c) Kim, S. H.; Kim, K. H.; Hong, S. H. Carbon Dioxide Capture and Use: Organic Synthesis Using Carbon Dioxide from Exhaust Gas. Angew. Chem., Int. Ed. 2014, 53, 771-774. (d) Liu, H. L.; Huang, Z. W.; Han, Z. B.; Ding, K. L.; Liu, H. C.; Xia, C. G.; Chen, J. Efficient Production of Methanol and Diols via the Hydrogenation of Cyclic Carbonates Using Copper-Silica Nanocomposite Catalysts. Green Chem. 2015, 17, 4281-4290. (e) Kalb, R. S.; Stepurko, E. N.; Emel'yanenko, V. N.; Verevkin, S. P. Carbonate Based Ionic Liquid Synthesis (CBILS®): Thermodynamic Analysis. Phys. Chem. Chem. Phys. 2016, 18, 31904-31913.

(11) (a) Luinstra, G. A. Poly(Propylene Carbonate), Old Copolymers of Propylene Oxide and Carbon Dioxide with New Interests: Catalysis and Material Properties. Polym. Rev. 2008, 48, 192-219. (b) Korashvili, R.; Noernberg, B.; Bornholdt, N.; Borchardt, E.; Luinstra, G. A. Poly(Propylene Carbonate) from Carbon Dioxide: Challenges for Large-Scale Application. Chem. Ing. Tech. 2013, 85, 437-446. (c) Langanke, J.; Wolf, A.; Hofmann, J.; Bohm, K.; Subhani, M. A.; Muller, T. E.; Leitner, W.; Gürtler, C. Carbon Dioxide $\left(\mathrm{CO}_{2}\right)$ as Sustainable Feedstock for Polyurethane Production. Green Chem. 2014, 16, 1865-1870. 
(12) Chapman, A. C.; Keyworth, C.; Kember, M. R.; Lennox, A. J. J.; Williams, C. K. Adding Value to Power Station Captured $\mathrm{CO}_{2}$ : Tolerant $\mathrm{Zn}$ and $\mathrm{Mg}$ Homogeneous Catalysts for Polycarbonate Polyol Production. ACS Catal. 2015, 5, 1581-1588.

(13) (a) North, M.; Pasquale, R. Mechanism of Cyclic Carbonate Synthesis from Epoxides and $\mathrm{CO}_{2}$. Angew. Chem., Int. Ed. 2009, 48, 2946-2948. (b) Jutz, F.; Buchard, A.; Kember, M. R.; Fredriksen, S. B.; Williams, C. K. Mechanistic Investigation and Reaction Kinetics of the Low-Pressure Copolymerization of Cyclohexene Oxide and Carbon Dioxide Catalyzed by a Dizinc Complex. J. Am. Chem. Soc. 2011, 133, 17395-17405. (c) Buchard, A.; Jutz, F.; Kember, M. R.; White, A. J. P.; Rzepa, H. S.; Williams, C. K. Experimental and Computational Investigation of the Mechanism of Carbon Dioxide/ Cyclohexene Oxide Copolymerization Using a Dizinc Catalyst. Macromolecules 2012, 45, 6781-6795. (d) Lehenmeier, M. W.; Kissling, S.; Altenbuchner, P. T.; Bruckmeier, C.; Deglmann, P.; Brym, A.-K.; Rieger, B. Flexibly Tethered Dinuclear Zinc Complexes: A Solution to the Entropy Problem in $\mathrm{CO}_{2} /$ Epoxide Copolymerization Catalysis? Angew. Chem., Int. Ed. 2013, 52, 9821-9826. (e) González-Fabra, J.; Castro-Gómez, F.; Kleij, A. W.; Bo, C. Mechanistic Insights into the Carbon Dioxide/Cyclohexene Oxide Copolymerization Reaction: Is One Metal Center Enough? ChemSusChem 2017, 10, 1233-1240.

(14) Moore, D. R.; Cheng, M.; Lobkovsky, E. B.; Coates, G. W. Mechanism of the Alternating Copolymerization of Epoxides and $\mathrm{CO}_{2}$ Using $\beta$-Diiminate Zinc Catalysts: Evidence for a Bimetallic Epoxide Enchainment. J. Am. Chem. Soc. 2003, 125, 11911-11924.

(15) Dengler, J. E.; Lehenmeier, M. W.; Klaus, S.; Anderson, C. E.; Herdtweck, E.; Rieger, B. A One-Component Iron Catalyst for Cyclic Propylene Carbonate Synthesis. Eur. J. Inorg. Chem. 2011, 2011, 336343.

(16) (a) Buonerba, A.; De Nisi, A.; Grassi, A.; Milione, S.; Capacchione, C.; Vagin, S.; Rieger, B. Novel Iron(III) Catalyst for the Efficient and Selective Coupling of Carbon Dioxide and Epoxides to Form Cyclic Carbonates. Catal. Sci. Technol. 2015, 5, 118-123. (b) Buonerba, A.; Della Monica, F.; De Nisi, A.; Luciano, E.; Milione, S.; Grassi, A.; Capacchione, C.; Rieger, B. Thioether-Triphenolate Bimetallic Iron(III) Complexes as Robust and Highly Efficient Catalysts for Cycloaddition of Carbon Dioxide to Epoxides. Faraday Discuss. 2015, 183, 83-95.

(17) Della Monica, F.; Vummaleti, S. V. C.; Buonerba, A.; De Nisi, A.; Monari, M.; Milione, S.; Grassi, A.; Cavallo, L.; Capacchione, C. Coupling of Carbon Dioxide with Epoxides Efficiently Catalyzed by Thioether-Triphenolate Bimetallic Iron(III) Complexes: Catalyst Structure-Reactivity Relationship and Mechanistic DFT Study. Adv. Synth. Catal. 2016, 358, 3231-3243.

(18) (a) Darensbourg, D. J.; Yarbrough, J. C.; Ortiz, C.; Fang, C. C. Comparative Kinetic Studies of the Copolymerization of Cyclohexene Oxide and Propylene Oxide with Carbon Dioxide in the Presence of Chromium Salen Derivatives. In Situ FTIR Measurements of Copolymer vs Cyclic Carbonate Production. J. Am. Chem. Soc. 2003, 125, 7586-7591. (b) Chisholm, M. H.; Zhou, Z. Concerning the Mechanism of the Ring Opening of Propylene Oxide in the Copolymerization of Propylene Oxide and Carbon Dioxide To Give Poly(propylene carbonate). J. Am. Chem. Soc. 2004, 126, 1103011039. (c) Whiteoak, C. J.; Kielland, N.; Laserna, V.; Castro-Gómez, F.; Martin, E.; Escudero-Adán, E. C.; Bo, C.; Kleij, A. W. Highly Active Aluminium Catalysts for the Formation of Organic Carbonates from $\mathrm{CO}_{2}$ and Oxiranes. Chem. - Eur. J. 2014, 20, 2264-2275. (d) Martín, C.; Kleij, A. W. Comparing Kinetic Profiles Between Bifunctional and Binary Type of $\mathrm{Zn}$ (salen)-Based Catalysts for Organic Carbonate Formation. Beilstein J. Org. Chem. 2014, 10, 1817-1825. (e) Castro-Osma, J. A.; Lamb, K. J.; North, M. $\mathrm{Cr}$ (salophen) Complex Catalyzed Cyclic Carbonate Synthesis at Ambient Temperature And Pressure. ACS Catal. 2016, 6, 5012-5025. (19) (a) Capacchione, C.; Proto, A.; Ebeling, H.; Mülhaupt, R.; Möller, K.; Spaniol, T. P.; Okuda, J. Ancillary Ligand Effect on SingleSite Styrene Polymerization: Isospecificity of Group 4 Metal Bis(phenolate) Catalysts. J. Am. Chem. Soc. 2003, 125, 4964-4965. (b) Capacchione, C.; Manivannan, R.; Barone, M.; Beckerle, K.; Centore, R.; Oliva, L.; Proto, A.; Tuzi, A.; Spaniol, T. P.; Okuda, J. Isospecific Styrene Polymerization by Chiral Titanium Complexes That Contain a Tetradentate [OSSO]-Type Bis(phenolato) Ligand. Organometallics 2005, 24, 2971-2982.

(20) Sellmann, D.; Freyberger, G.; Eberlein, R.; Bohlen, E.; Huttner, G.; Zsolnai, L. Übergangsmetallkomplexe mit Schwefelliganden: XXVI. Regiospezifische Templatalkylierungen an $\left[\mathrm{FeII}(\mathrm{CO})_{2}\right]$ Zentren: Synthese und Struktur der Eisen(II)-Komplexe $\left[\mathrm{FeL}^{1} \mathrm{~L}^{2}\left({ }^{t} \mathrm{Bu}_{4}\right.\right.$-dttd)] Mit dem Sterisch Anspruchsvollen Vierzähnigen Thioether-Thiolatliganden ${ }^{t} \mathrm{bu}_{4}$ - $\mathrm{dttd}^{2}=$ (tetra-t-butyl)-2,3;8,9-dibenzo-1,4,7,10-tetrathiadecan $(2-) ;\left(\mathrm{L}^{1}=\mathrm{L}^{2}=\mathrm{CO}, \mathrm{PMe}_{3} ; \mathrm{L}^{1}=\mathrm{CO}, \mathrm{L}^{2}=\right.$ $\mathrm{Pme}_{3}, \mathrm{PPh}_{3}$ ). J. Organomet. Chem. 1987, 323, 21-35.

(21) Wu, X.; North, M. A Bimetallic Aluminium(Salphen) Complex for the Synthesis of Cyclic Carbonates from Epoxides and Carbon Dioxide. ChemSusChem 2017, 10, 74-78.

(22) (a) Paddock, R. L.; Nguyen, S. T. Chemical $\mathrm{CO}_{2}$ Fixation: $\mathrm{Cr}$ (III) Salen Complexes as Highly Efficient Catalysts for the Coupling of $\mathrm{CO}_{2}$ and Epoxides. J. Am. Chem. Soc. 2001, 123, 11498-11499. (b) Darensbourg, D. J.; Fang, C. C.; Rodgers, J. L. Catalytic Coupling of Carbon Dioxide and 2,3-Epoxy-1,2,3,4tetrahydronaphthalene in the Presence of a (Salen) $\mathrm{Cr}^{\mathrm{III}} \mathrm{Cl}$ Derivative. Organometallics 2004, 23, 924-927. (c) Darensbourg, D. J.; Bottarelli, P.; Andreatta, J. R. Inquiry Into the Formation of Cyclic Carbonates During the (Salen)CrX Catalyzed $\mathrm{CO}_{2} /$ Cyclohexene Oxide Copolymerization Process in the Presence of Ionic Initiators. Macromolecules 2007, 40, 7727-7729. (d) Zhang, X.; Jia, Y.-B.; Lu, X.-B.; Li, B.; Wang, H.; Sun, L.-C. Intramolecularly Two-Centered Cooperation Catalysis for the Synthesis of Cyclic Carbonates from $\mathrm{CO}_{2}$ and Epoxides. Tetrahedron Lett. 2008, 49, 6589-6592.

(23) (a) Buchard, A.; Kember, M. R.; Sandeman, K. G.; Williams, C. K. A Bimetallic Iron(III) Catalyst for $\mathrm{CO}_{2} /$ Epoxide Coupling. Chem. Commun. 2011, 47, 212-214. (b) Nakano, K.; Kobayashi, K.; Ohkawara, T.; Imoto, H.; Nozaki, K. Copolymerization of Epoxides with Carbon Dioxide Catalyzed by Iron-Corrole Complexes: Synthesis of a Crystalline Copolymer. J. Am. Chem. Soc. 2013, 135, 8456-8459. (c) Taherimehr, M.; Al-Amsyar, S. M.; Whiteoak, C. J.; Kleij, A. W.; Pescarmona, P. P. High Activity and Switchable Selectivity in the Synthesis of Cyclic and Polymeric Cyclohexene Carbonates with Iron Amino Triphenolate Catalysts. Green Chem. 2013, 15, 3083-3090. (d) Taherimehr, M.; Sertã, J. P. C. C.; Kleij, A. W.; Whiteoak, C. J.; Pescarmona, P. P. New Iron PyridylaminoBis(Phenolate) Catalyst for Converting $\mathrm{CO}_{2}$ into Cyclic Carbonates and Cross-Linked Polycarbonates. ChemSusChem 2015, 8, 10341042.

(24) Allen, S. D.; Moore, D. R.; Lobkovsky, E. B.; Coates, G. W. High-Activity, Single-Site Catalysts for the Alternating Copolymerization of $\mathrm{CO}_{2}$ and Propylene Oxide. J. Am. Chem. Soc. 2002, 124, 14284-14285.

(25) (a) D’Elia, V.; Dong, H.; Rossini, A. J.; Widdifield, C. M.; Vummaleti, S. V. C.; Minenkov, Y.; Poater, A.; Abou-Hamad, E.; Pelletier, J. D. A.; Cavallo, L.; Emsley, L.; Basset, J.-M. Cooperative Effect of Monopodal Silica-Supported Niobium Complex Pairs Enhancing Catalytic Cyclic Carbonate Production. J. Am. Chem. Soc. 2015, 137, 7728-7739. (b) D’Elia, V.; Ghani, A. A.; Monassier, A.; Sofack-Kreutzer, J.; Pelletier, J. D. A.; Drees, M.; Vummaleti, S. V. C.; Poater, A.; Cavallo, L.; Cokoja, M.; Basset, J.-M.; Kühn, F. E. Dynamics of the $\mathrm{NbCl}_{5}$-Catalyzed Cycloaddition of Propylene Oxide and $\mathrm{CO}_{2}$ : Assessing the Dual Role of the Nucleophilic Co-Catalysts. Chem. - Eur. J. 2014, 20, 11870-11882.

(26) Minenkov, Y.; Wang, H.; Wang, Z.; Sarathy, S. M.; Cavallo, L. Heats of Formation of Medium-Sized Organic Compounds from Contemporary Electronic Structure Methods. J. Chem. Theory Comput. 2017, 13, 3537-3560. 